\title{
Hydrolysis Lignin as a Sorbent and Basis for Solid Composite Biofuel
}

\section{Huo Po1, Savitskaya Tatsiana², Reznikov Ivan'2, Hrynshpan Dzmitry³, Tsygankova Nadejda ${ }^{3}$, Telysheva Galina ${ }^{4}$, Arshanitsa Alexandr ${ }^{4}$}

${ }^{1}$ College of Biology and Environmental Engineering, Zhejiang Shuren University, Hangzhou, China

${ }^{2}$ Faculty of Chemistry, Belarusian State University, Minsk, Belarus

${ }^{3}$ Research Institute for Physical and Chemical Problems, Minsk, Belarus

${ }^{4}$ Latvian State Institute of Wood Chemistry, Riga, Latvia

Email: savitskayaTA@bsu.by, ivanreznikov@gmail.com

How to cite this paper: Po, H., Tatsiana, S., Ivan, R., Dzmitry, H., Nadejda, T., Galina, T. and Alexandr, A. (2016) Hydrolysis Lignin as a Sorbent and Basis for Solid Composite Biofuel. Advances in Bioscience and Biotechnology, 7, 501-530.

http://dx.doi.org/10.4236/abb.2016.711046

Received: September 19, 2016

Accepted: November 27, 2016

Published: November 30, 2016

Copyright $\odot 2016$ by authors and Scientific Research Publishing Inc. This work is licensed under the Creative Commons Attribution International License (CC BY 4.0).

http://creativecommons.org/licenses/by/4.0/

(c) (i) Open Access

\begin{abstract}
New powdered sorbent Lignosorb based on the hydrophobized hydrolysis lignin has been developed at the Belarusian State University. Hydrolysis lignin is a commercial waste product of biomass processing in the hydrolysis production of ethanol. In spite of the various proposals for hydrolysis lignin usage, the wide application has not found yet. Special area of hydrophobized hydrolysis lignin usage as a sorbent for oil spills removal and oil products waste recovery is discussed. Lignosorb, thanks to the rather high bulk density, can be applied manually or mechanically by conventional sprayers. It does not sink after oil adsorption and transforms liquid oil film on the water surface into the solid mass. The solid product is a complete mass and is easily collected from the surface of water. Lignosorb when blended with oil products waste in the volume forms the granular free-running product. The rheological properties of the Lignosorb suspensions in oil products at different sorbent to oil product ratio have been estimated. Saturated by different oil products Lignosorb one can granulate or pellet and utilize as a composite solid fuel including the co-firing regime of combustion. It has the higher heating value of 32.1 - 38.8 MJ/kg while the coal has 20.9 $30.1 \mathrm{MJ} / \mathrm{kg}$. It has been shown that composite fuel burning has less longstanding inflammation stage, more long stable burning stage and less longstanding phase of smoldering in the comparison to wood and Lignosorb burning.
\end{abstract}

\section{Keywords}

Lignin, Sorbent, Oil Spills, Oil Products Waste, Composite Fuel

\section{Introduction}

Oil is one of the most dangerous pollutants for the environment because of its capacity 
to thin the lipid layers of the cells membrane and the huge scale of usage. The impact of oil spills on water ecosystem cannot be overemphasized. One liter of oil when poured into water denudes forty liters of it of oxygen and can work the ruin more than one million of larval or hatchling fish and other sea organisms [1]. According to the United States National Research Council reports up to ten million oil tons fall into rivers, lakes and global ocean annually. Risk of crude oil and refined products pollution coming from spills and leakages at transportation, transfers and accumulation of oil effluent at different oil field operations will increase in future as oil consumption increases [2]. However, the story is not complete, because of the fact that Russian scientists discovered the oil at the age of fifty that can be tolerated as the evidence of its renewability [3].

Although to date numerous oil spills and waste cleanup recovery technologies have been developed, the problem in general is not considered as totally solved. Common solutions and projects include in-situ burning of oil on water, mechanical tools (booms, skimmers and novel devices as powerful hydrodynamic laser [4], use of chemical dispersants, steam flushing, solidifiers, different kind of sorbents, involving, inter alia, carbon nanofiber and nanocellulose aerogels [5] [6], and biodegradation agents that are effective on shorelines or land.

Among these items, the sorption methods are important in allowing us to provide the desired degree of oil removal, even of oil traces, easy for automating and call for low operating cost. Sorbent materials are attractive for some applications because of the possibility of collection and complete removal of the oil from the oil spill site or the waste storage. The ideal sorbent material needs to be both oleophilic and hydrophobic to have high rate uptake and capacity, retention over time, oil recovery from the sorbent, reusability and biodegradability. Some of these properties have overlapping aspects. While all are desirable for a sorbent, ultimate selection of the best material will involve a comparison between the most essential properties and other factors such as material availability, use experience in practice, available equipment for distribution and harvesting, oil product nature, location, etc. Of primary interest are the buoyancy retention, oil sorption capacity and easy separation of oil for re-use or cost efficient recovery [7].

Because of the increasing number of oil spill accidents and the volume of petroleum products wastes the considerable attention has been paid to the development of effective, inexpensive, ecologically friendly oil sorbents taking into account the amount of solid waste generated after a cleanup operation and safety aspects of attempting to reuse.

Of special interest in this aspect is the technical hydrolysis lignin (HL) as organic natural sorbent. At present time, in spite of the various proposals for using lignin, which is a large-tonnage by-product of the hydrolysis industry, wide application has not found yet. Lignin is accumulated at enterprises, occupying large territories and threatening the environment [8]. It is little studied as a sorbent for oil spills that may be due to discharge of crude oil or its derived products such as gasoline, diesel or machine oil from tankers, ships, offshore platforms and so on [9]. 
Research Institute for Physical and Chemical Problems has developed the method of the initial lignin hydrophobization. This procedure includes mixing of high wet samples of lignin with dried ones. Hydrophobized hydrolysis lignin (HHL) can be used for oil products recovery. In this article, we report on the results of the evaluation of hydrophobized hydrolysis lignin as the oil sorbent, colloidal-chemical properties of lignin-in-oil products dispersions, and the characteristics of the composite solid fuel based on the oil saturated hydrolysis lignin.

\section{Materials and Methods}

\subsection{Materials}

The hydrolysis lignin (acid hydrolysis) obtained from the dumps of the Republic of Belarus Unitary Enterprise "Rhechitskii Pilot-Production Plant" and Open Joint Stock Company "Bobruisk Plant of Biotechnologies" were used as the main samples to study (sample 1 and 2). For the comparison study the enzymatic hydrolysis lignin (Sweden, sample 3) and organosolv lignin (ALCELL, Sweden, sample 4) were taken as well. Lignins' characteristics were estimated and are given in Table 1.

The mass fraction of acids expressed in terms of sulphuric and acetic acids corresponds to $0.8 \%$ and $3.6 \%$ for samples 1 and 2 consequently. The humidity of the initial lignins was no more than $70 \%$, after hydrophobization by drying in special regime the moisture content varied under $25 \%$.

The characteristics of oil products under study are given in Table 2.

\subsection{Procedure of Oil Products-Lignin Systems Preparation}

Oil dispersions of lignin with a content of the dispersed phase from 5 to 46 wt.\% were prepared for study by the gravimetric method with subsequent agitation in an IKA WERKE mechanical impeller agitation (Germany) for $10 \mathrm{~min}$ with a velocity of 500 rpm just before rheological measurements. Mixing of lignin with oil layer on the water surface was made by manually spraying of lignin that spontaneously mixes up with oil.

\subsection{Procedure of Combined Fuel Pellets Based on Oil Products and Lignin}

The samples of lignin saturated by oil product were pressed with a $5 \times 10^{7} \mathrm{~Pa}$ hydraulic

Table 1. Characteristics of lignin samples.

\begin{tabular}{|c|c|c|c|c|c|c|c|c|c|c|c|}
\hline \multirow{2}{*}{ 䒕 } & \multirow{2}{*}{$\begin{array}{c}\text { Content of } \\
\text { Klason } \\
\text { lignin, \% }\end{array}$} & \multirow{2}{*}{$\begin{array}{c}\text { Bulk } \\
\text { density, } \\
\mathrm{kg} / \mathrm{m}^{3}\end{array}$} & \multirow{2}{*}{$\begin{array}{l}\text { Absolute } \\
\text { density by } \\
\text { helium, } \\
\mathrm{kg} / \mathrm{cm}^{3}\end{array}$} & \multicolumn{3}{|c|}{$\begin{array}{c}\text { Functional group } \\
\text { content, } \%\end{array}$} & \multicolumn{5}{|c|}{ Content of elements, $\%$} \\
\hline & & & & $\mathrm{OCH}_{3}$ & $\mathrm{OH}_{\text {acet }}$ & $\mathrm{OH}_{\text {phen }}$ & $\mathrm{OH}_{\text {alif }}$ & $\mathrm{C}$ & $\mathrm{H}$ & $\mathrm{N}$ & $S$ \\
\hline 1 & 69.6 & 240 & 1484 & 6.9 & 6.1 & 2.7 & 3.4 & 52.8 & 4.72 & 0.43 & 0.22 \\
\hline 2 & 68.5 & 360 & 1493 & 7.61 & 8.1 & 8.1 & 5.8 & 49.5 & 4.45 & 0.25 & 0.74 \\
\hline 3 & 74.6 & 180 & 1329 & 11.4 & 1.3 & 3.6 & 3.2 & 60.9 & 5.93 & 1.13 & 0.34 \\
\hline 4 & 84.6 & 160 & 1287 & 8.6 & 9.0 & 1.2 & 7.8 & 66.7 & 4.92 & 0.15 & 0.23 \\
\hline
\end{tabular}


Table 2. Characteristics of the oil products.

\begin{tabular}{ccccc}
\hline Kind of oil product & Density, g/cm & $\begin{array}{c}\text { Surface Tension, } \\
\sigma \cdot 10^{3} \mathrm{~N} / \mathrm{m}\end{array}$ & Viscosity, mPa.s & Content of sulpha, \% \\
\hline Crude oil & 0.81 & 28.6 & 134.97 & 0.28 \\
Diesel Fuel & 0.8 & 30.8 & 5.9 & 0.15 \\
$\begin{array}{c}\text { Industrial oil } \\
\text { (SAE 15 W-40) }\end{array}$ & 0.83 & 27.75 & 319.01 & 1.5 \\
Gasoline & 0.78 & 21.15 & 0.56 & 0.05 \\
\hline
\end{tabular}

The worked out engine oil BMW Original was used as well.

press. The final pressure for sample production of $10 \mathrm{GPa}$ was reached at a controlled pressing rate of $100 \mathrm{MPa} / \mathrm{s}$. Cylinder shaped pellets with a diameter of $15 \mathrm{~mm}$ and a typical thickness of $10-20 \mathrm{~mm}$ were produced.

\subsection{Applied Methods and Procedures for Studying Oil Products-Lignin Systems}

\subsubsection{Rheological Method}

The "Rheotest-2" rheoviscosimeter (Germany) was used for the evaluation of the rheological properties of diluted and middle concentrated lignin dispersions in the range of shear stresses 4 - 800 Pa. "Brookfield" rotary rheometer (USA) with Rheo3000 software and a measuring system with CC25 coaxial cylinders was under study in the area of 11.4 - $1140 \mathrm{~Pa}$ for the dispersions with a lignin content over $40 \%$. The hysteresis at a temperature of $298 \pm 1 \mathrm{~K}$ was studied in the regime of increasing and decreasing shear stress with the same rate. The duration of the experiment with measurement in one direction was $2 \mathrm{~min}$ with the use of "Rheotest-2" rheometer and $20 \mathrm{~s}$ with the use of the "Brookfield" rheometer. The obtained data were presented as flow curves.

\subsubsection{BET Analysis}

Specific surface area and pore size distributions were measured using a Gemini 2360 (Micromeritics, USA) through nitrogen adsorption at $77 \mathrm{~K}$ in the range of relative pressure $\left(\mathrm{P} / \mathrm{P}_{0}\right)$ of $10^{-6}-1$. Sample preparation involved degassing the samples overnight ( 16 hours) at $120^{\circ} \mathrm{C}$ under vacuum. The samples were subjected to 99-point BET surface area analysis and full adsorption isotherms were collected for all samples. In addition, micropore and mesopore volume distribution as a function of pore size were calculated based on the Horvath-Kawazoe (HK) and Barret, Joyner and Halenda (BJH) method, respectively.

\subsubsection{Thermal Analysis}

Thermal analysis of lignin and oil samples was carried out by differential scanning calorimetry (DSC) and thermogravimetry (TG) using a Simultaneous Thermal Analyzer "STA 449 Jupiter" produced by "NETZSCH" (Bayern) in nitrogen atmosphere. DSC and TG curves were recorded in the range of $100^{\circ} \mathrm{C}-600^{\circ} \mathrm{C}$, the weight of the samples was about $10 \mathrm{mg}$. The samples were placed in standard corundum crucibles. 
Sensitivity of DSC is $1 \mathrm{mkVt}$, the measurement error is $7 \%$; TG sensitivity $-1 \times 10^{-7} \mathrm{~g}$, the measurement error of weight loss is $1 \times 10^{-6} \mathrm{~g}$.

\subsubsection{Contact Angles Measurement}

Static and dynamic contact angles were measured using a FTA200 computer-controlled, video-based instrument (First Ten Angstroms, USA). The instrument is built around rapid video capture of images and automatic image analysis. The instrument includes a CCD video camera, a frame grabber, an adjustable sample stage and a LED light source. A drop $(1 \mu \mathrm{l})$ of test liquid (water, diesel, hydraulic oil or engine oil) was allowed to fall onto the sample from a syringe tip to produce a sessile drop. The drop was dispensed from a syringe pump driven by a stepper motor. Images were captured at a rate of 10 frames per second for $10 \mathrm{~s}$. In this study, single images (a snapshot) as well as image sequences (a movie) were captured.

\subsubsection{Dispersion Analysis}

The method of laser scattering was used for dispersion analysis. The measurement of particle size was performed on Mastersizer 3000 together with Aero S disperser (both"Malvern"). In order to provide enough data for statistical analysis, the sample weight appeared to be $10 \mathrm{~g}$.

\subsubsection{Solidity Test}

Water waves in an ecological real-life model experiment, described below were generated by KS 260 control shaker (IKA). A found rpm frequency-wave height dependence allowed to simulate the behavior of the composite on the water surface. In addition, we placed certain weights on the solidified oil layer to measure the floating ability and the strength of the solidified layer. The total mass of weights reached 17 grams per $7.5 \mathrm{~cm}^{2}$ without the breakdown of the compact layer.

\subsubsection{Determination of Moisture Content}

To determine the moisture content of the sample, a mass of $0.5 \mathrm{~g}$ (accuracy of weighing $0.0002 \mathrm{~g}$ ) was adjusted to a constant mass weighing bottle. An open weighing bottle was heated in an oven at $(378 \pm 5) \mathrm{K}$ for 2 hours, followed by cooling in a desiccator with calcined $\mathrm{CaCl}_{2}$. Drying process was performed to constant weight [10].

Moisture content of the sample was calculated according to the formula:

$$
w=\frac{\left(m_{2}-m_{1}\right) \cdot 100}{m}
$$

where $m_{2}-$ mass of initial sample, g;

$m_{1}$-mass of the sample after drying, g.

\subsubsection{Determination of Fractional Composition of Lignin}

Separation of the sorbent particle by diameters was performed by sieving with a set of four screens and a tray. A sample of sorbent $(100 \mathrm{~g})$ was poured into the middle of the top screen kit and sieved for 15 minutes. After the residue on each sieve, the sorbent was poured onto a separate tray and the weight of each fraction was determined with an 
accuracy up to $0.02 \mathrm{~g}$.

The content of a fraction of the sorbent particles $(X)$ was calculated according to the formula:

$$
X=\frac{m_{i} \cdot 100}{M}
$$

where $M$-mass of non-fractioned sorbent, g;

$$
m_{i} \text {-sorbent mass on } i \text {-tray after sieving, g. }
$$

\subsubsection{Determination of Bulk Density}

Dried to constant weight lignin was poured into a pre-weighed measuring vessel with a height of $100 \mathrm{~mm}$ above its top edge to form a cone over the top of the vessel, which was removed by a metal ruler (without tight packing of the sample) and weighed.

The bulk density of the sorbent $\left(\rho_{b}\right)$ in $\mathrm{kg} / \mathrm{m}^{3}$ was determined with an accuracy up to $10 \mathrm{~kg} / \mathrm{m}^{3}$ according to the formula:

$$
\rho_{b}=\frac{m_{1}-m_{2}}{V}
$$

where $m_{1}$-weight of the vessel with the filler, $\mathrm{kg}$;

$m_{2}$-weight of the vessel, $\mathrm{kg}$;

$V$-volume of the vessel, $\mathrm{m}^{3}$.

The bulk density of the sorbent was calculated as the arithmetic mean of the results of four determinations.

\subsubsection{Determination of Oil Absorption Capacity}

$$
w_{c}=\frac{\left(m_{2}-m_{1}\right)}{m_{1}}
$$

A certain mass sample was placed into a cylinder (diameter $20 \mathrm{~mm}$, height $50 \mathrm{~mm}$ ), made of a metal net with openings $h=0.1 \mathrm{~mm}$. The cylinder was tightly capped and placed in a vial with the model oil composition at $\mathrm{T}=25^{\circ} \mathrm{C}$, so that the liquid level above the top of the cylinder was not less than $20 \mathrm{~mm}$ above the sorbent. In this position, the sample was kept for 24 hours. The cylinder has been removed from the vessel followed by the drainage of unabsorbed oil for 1 hour. After a dry cloth was used to wipe away the surface of the cylinder. The net was weighed with an error less than $0.1 \mathrm{~g}$. Oil absorption capacity $W_{c}$ was calculated according to the formula:

where $m_{1}$ - the mass of dry sample, g;

$m_{2}$ - the mass of the sample after oil adsorption, $\mathrm{g}$.

The result was determined as an arithmetic mean of the three independent results.

\subsubsection{Determination of the Retention Time on the Water Surface of the Sorbent in Oil-Saturated State}

In laboratory glasses $\mathrm{V}=100 \mathrm{~cm}^{3} 50 \mathrm{~cm}^{3}$ of water was poured together with $2-5 \mathrm{~cm}^{3}$ of model oil composition. The mass of the sorbent was added to follow the ratio $1 \mathrm{~g}$ of sorbent per $2 \mathrm{~g}$ of oil. The retention time was determined. 


\section{Results and Discussion}

Lignin is one of the three major compounds of biomass along with cellulose and hemicellulose. Biosphere has an estimated $3 \times 10^{11}$ metric tons of lignin with a $2 \times 10^{10}$ metric tons annual biosynthesis rate. Lignin has complicated chemical and topological structure. The main buildings block of lignin isconiferyl, sinapyl and coumaryl alcohol [10], shown on Figure 1.

The fragments are randomly conglomerated together to compose cell walls of plants and maintain the integrity of the cellulose/hemicellulose/pectin matrix [11].

An important point is the structure of lignin macromolecules. Novel hypothesis was put forward that is concerned the existence of different universal lignin classes having diversity of topological structures [12]. This means that the molecules of lignin extracted from different kinds of plants have their own structure. They have different shapes including coil, linear structure, star, dendrites, and so on.

Computational results obtained using software programs from Dassault Systèmes BIOVIA. The ab initio calculations were performed with the DMol3 program, and graphical displays generated with BIOVIA Materials Studio. The Nimz lignin fragment [13] was geometrically optimized using the MNDO method. The complex surface structure is shown in Figure 2.

It is seen from Figure 2(a) that oxygenatomcontent (highlighted with red color) is quite high (14.6\% by number, $30.5 \mathrm{wt} . \%)$. Being the negative charged atoms in lignin fragment, it is though seen, that the interpolated charge map (Figure 2(b)) does not completely match with the figure abovementioned (Figure 2(a)). The Solvent Excluded surface (or Connolly surface) is defined as the locus of the inward-facing probe sphere as it rolls over the van der Waals surface of the molecule. This surface can be considered as a continuous sheet consisting of two parts: the contact surface and the reentrant surface.

The contact surface is a part of the van der Waals surface that is accessible to a probe sphere. The re-entrant surface is the inward-facing surface of the probe when it touches two or more atoms. Both surfaces were created in Discovery Studio 2.5 using $1.4 \mathrm{~A}$ Connoly radius and vdW factor 1 .

As different colors on Figure 2(b) represent different charge, one can see, that blue color, consisted of only $\mathrm{C}$ and $\mathrm{H}$ atoms, represent the hydrophobic part of the fragment.
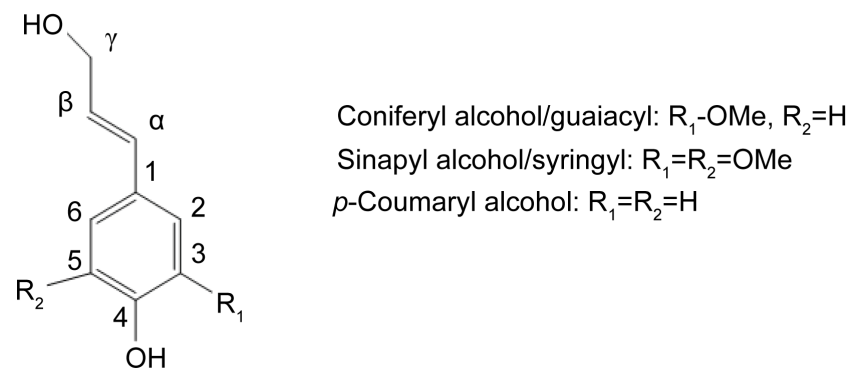

Figure 1. Three main building blocks of lignin. 


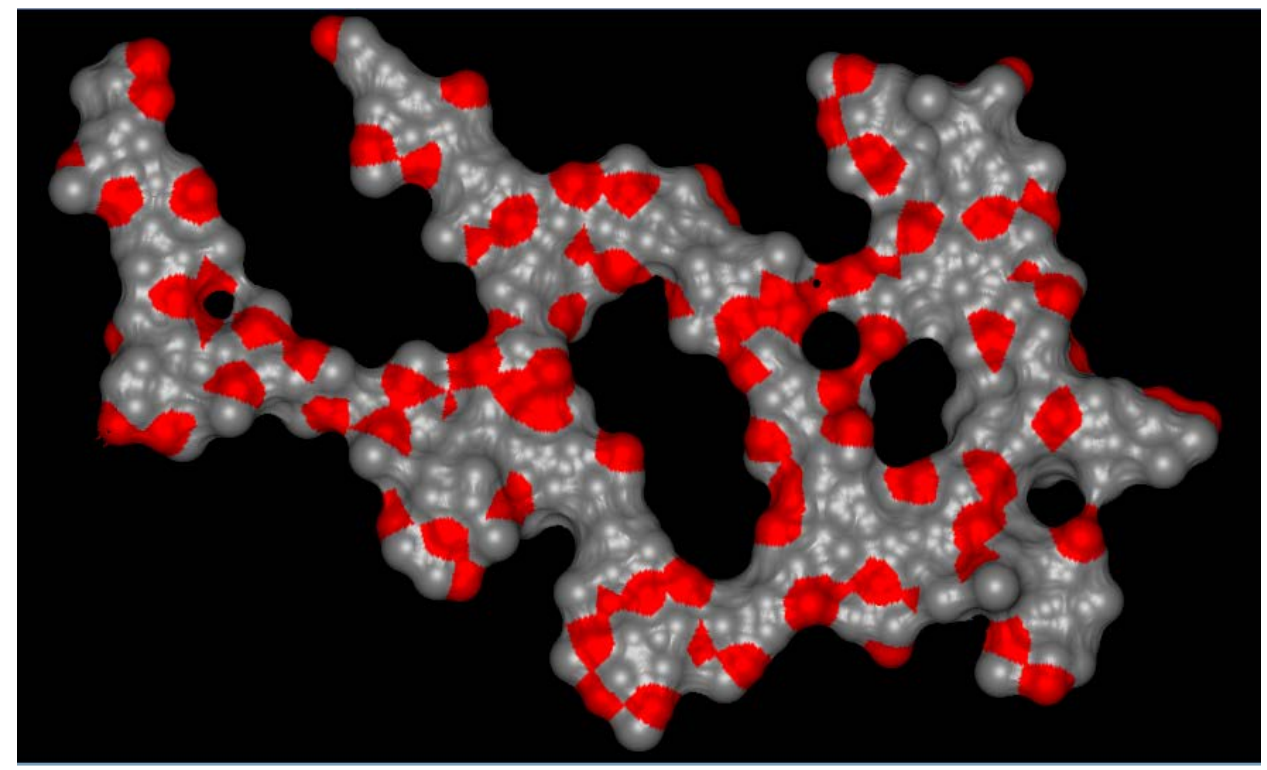

(a)

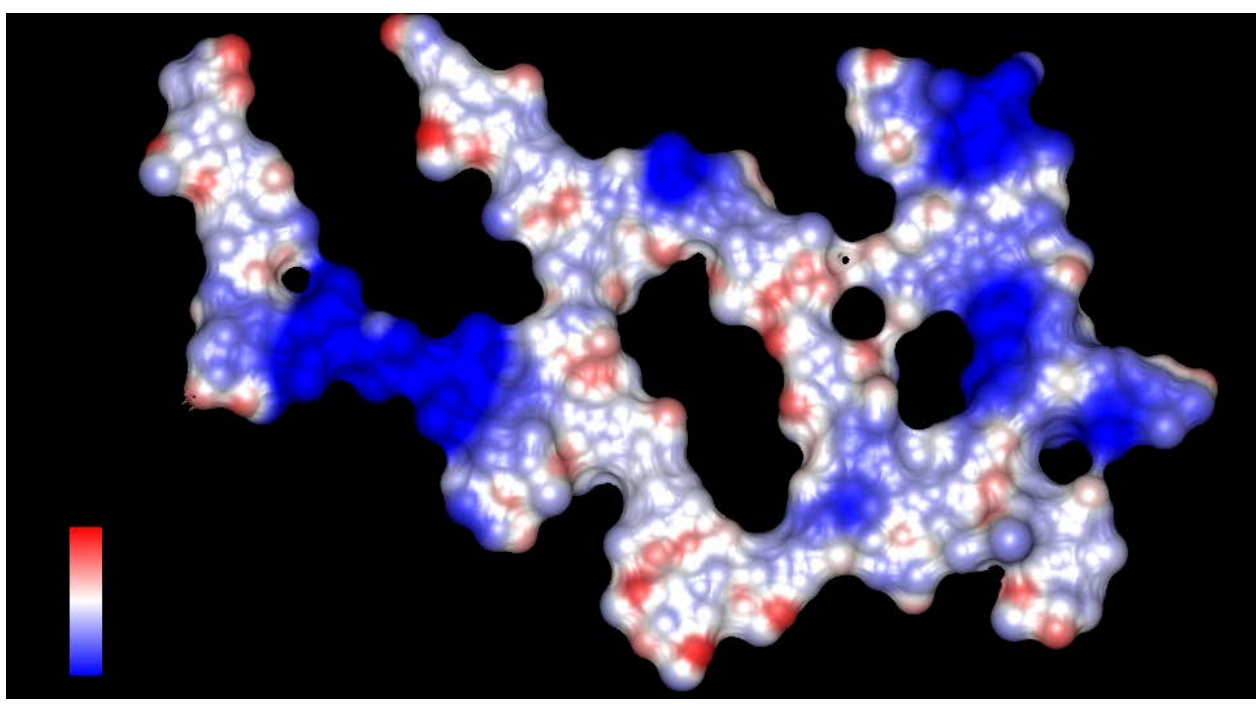

(b)

Figure 2. Connoly surfaceof alignin fragment structure [13] with probe radius 1.4A. (a) Colored by atom; (b) By interpolated charge.

Compared to hydrophilic red "spots", hydrophobic areas are grouped together, allowing interactions with large organic hydrophobic molecules. This lead to the possibility of both sorbing polar and non-polar molecules.

The following computer aproximation allows to presume the fact that the certain material can be a sorbent, as one can surmise the hydrophobization process decrease the "polar" area of the structure due to volatilization of weakly bound groups.

Hydrolysis lignin (HL) is produced as a by-product at the ethanol (hydrolysis alcohol) production. In this production, lignin, which contains no sugar units, is separated by percolation acid hydrolysis by diluted $\mathrm{H}_{2} \mathrm{SO}_{4}$ from the cellulose and hemicelluloses, 
which do contain sugar units. HL, which is still in its solid form after lignocellulosic ethanol production, has different spheres for use: in energy sector for the production of briquettes, pellets; pyrolysis bio-oil and fuel gas; in chemical industry as a sorbent for purification of industrial effluents; in agriculture for the production of fertilizers, herbicides, and so on.

An up-growing interest to biofuels prompted the investigations on lignin fermentation and chemical biological transformations to low-molecular-weight organic matter. Unfortunately, the initial role of lignin in nature is to protect cell wall polysaccharides from microbial degradation. Thus, it is not surprising that the biodegradability of lignin appears to be quite low, and the only palisade wood-destroying fungi causing of the white rot (Coriolus versicolor, Fomes fomentarius) and some nesting basidimycetes (Collybria, Marasmius, Mycena) activated the degradation of lignin [14]. There are some trends of research on the alternative uses of lignin including the production of activated carbon, carbon fibers and phenols as well. Lignin based products are very attractive because of REACH as a possible barrier for future European market development is not specific to them [15].

\subsection{Dispersion Analysis}

The hydrophobized HLunder study was a deep dark brown powder mass with rather wide distribution of particles by size that differs from the narrower distribution of the lignin samples obtained by the enzymatic hydrolysis or the organosolv process (Figure $3)$.

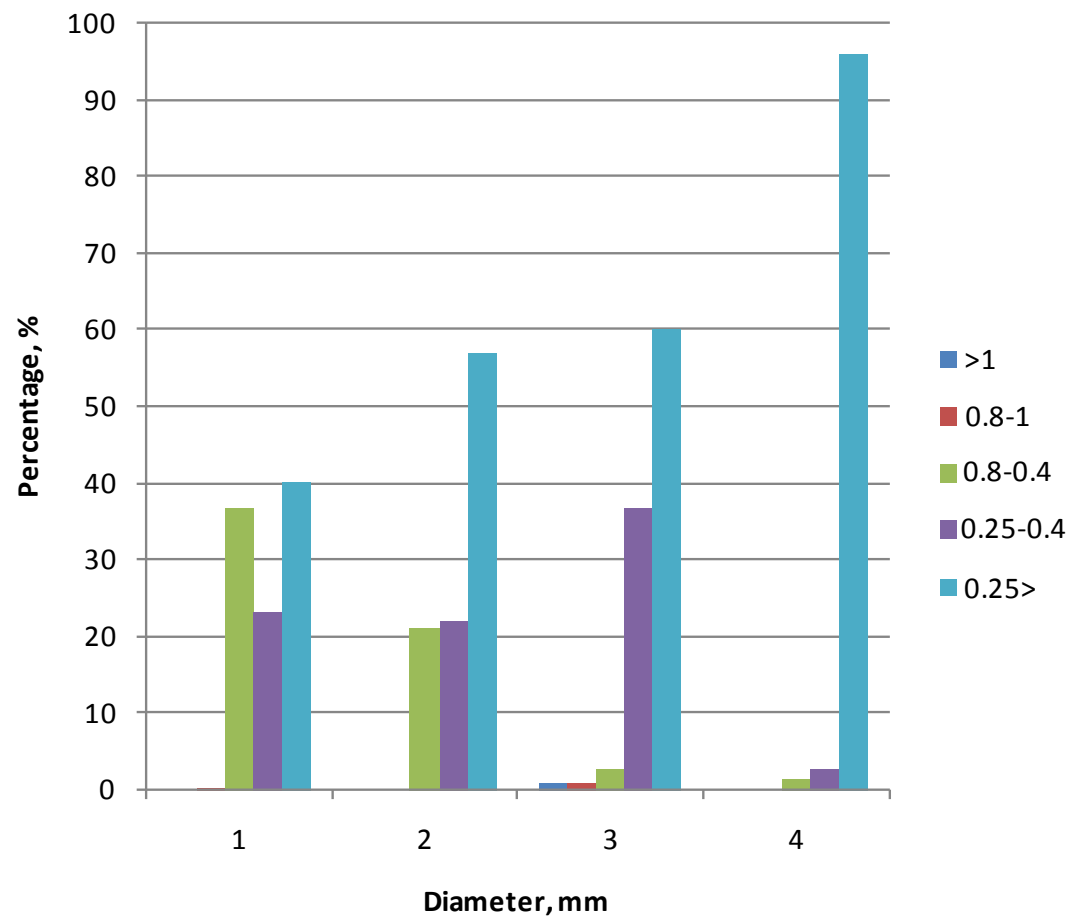

Figure 3. The diagrams of the particle sizes distribution for lignin samples (1-4). 
By the laser diffraction method, the statistic parameters of the particle size distribution were determined for HL samples 1. 2. Table 3 presents the difference in dispersity for the samples from different producers.

It has been shown on the lignin fraction sample $(0.4-0.8 \mathrm{~mm})$ that the particle size distribution in water as a dispersed media as compared to the dispersion with the air dispersed media becomes wider according to the aggregation of the lignin particles in water (see Table 4).

\subsection{Hydrolysis Lignin Structure and Sorption Capacity}

Figure 4 illustrates the IR spectrum of HL (sample 1). Judging by the IR spectrum data the sample contains significant amounts of carbohydrates. The evidence is the intense absorption bands in the $1000-1200 \mathrm{~cm}^{-1}$ range. The content of functional groups in the sample was shown earlier (Table 1).

The characteristics of the porous structure for different lignin samples: specific surface and pores sizes distribution was calculated by the software for Costech sorptometru KELVIN 1042 device according to the low temperature nitrogen sorption-desorption isotherms. The isotherms (Figure 5) correspond to the type II according to IUPAC classification. They are similar to the isotherms for the adsorbents with macro porous

Table 3. The calculated ANOVA parameters for hydrophobized HLsamples.

\begin{tabular}{ccc}
\hline Parameter & $\begin{array}{c}\text { Lignin } \\
\text { (“Rhechitskii pilot-production plant”) } \\
\text { Sample 1 }\end{array}$ & $\begin{array}{c}\text { Lignin } \\
\text { (“Bobruisk Plant of Biotechnologies”) } \\
\text { Sample 2 }\end{array}$ \\
\hline Dv 10. mm & 0.43 & 0.06 \\
Dv 50. mm & 0.71 & 0.33 \\
Dv 90. mm & 1.13 & 0.89 \\
$\mathrm{~S}_{\mathrm{h}}, \mathrm{m}^{2} / \mathrm{kg}$ & 10.2 & 35.2 \\
Weighted Residual, \% & 0.76 & 0.35 \\
Laser obscuration, \% & 17.3 & 3.09 \\
\hline
\end{tabular}

Table 4. ANOVA parameters for suspensions of different fractions of lignin particles in air and water media.

\begin{tabular}{|c|c|c|c|c|c|c|}
\hline \multirow{2}{*}{ Parameter } & \multicolumn{3}{|c|}{$\begin{array}{l}\text { Particle size of the fractionated sample } \\
\text { in air, } \mathrm{mm}\end{array}$} & \multicolumn{3}{|c|}{$\begin{array}{l}\text { Particle size of the fractionated sample } \\
\text { in water, } \mathrm{mm}\end{array}$} \\
\hline & $<0.2$ & $0.2-0.4$ & $0.4-0.8$ & $<0.2$ & $0.2-0.4$ & $0.4-0.8$ \\
\hline Dv $10 . \mathrm{mm}$ & 0.03 & 0.06 & 0.07 & 0.04 & 0.05 & 0.07 \\
\hline Dv $50 . \mathrm{mm}$ & 0.09 & 0.33 & 0.32 & 0.10 & 0.19 & 0.32 \\
\hline Dv $90 . \mathrm{mm}$ & 0.22 & 0.89 & 0.73 & 0.21 & 0.44 & 0.73 \\
\hline $\mathrm{S}_{\mathrm{h}}, \mathrm{m}^{2} / \mathrm{kg}$ & 80.3 & 35.2 & 29.5 & 54.8 & 37.9 & 29.5 \\
\hline Weighted Residual, \% & 0.19 & 0.30 & 0.50 & 0.22 & 0.27 & 0.51 \\
\hline Laser obscuration, \% & 0.29 & 0.96 & 0.50 & 6.13 & 4.03 & 5.45 \\
\hline
\end{tabular}




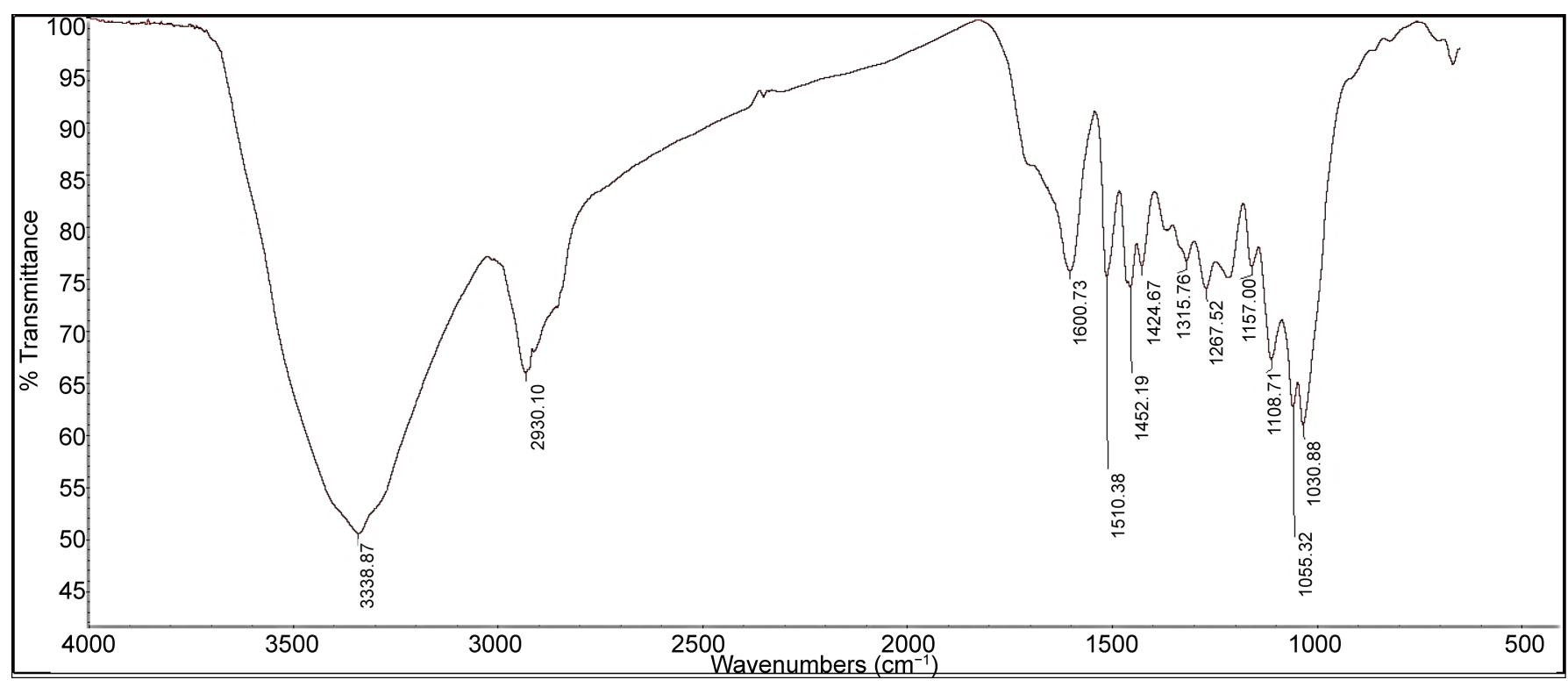

Figure 4. IR spectrum of HL (sample 1).

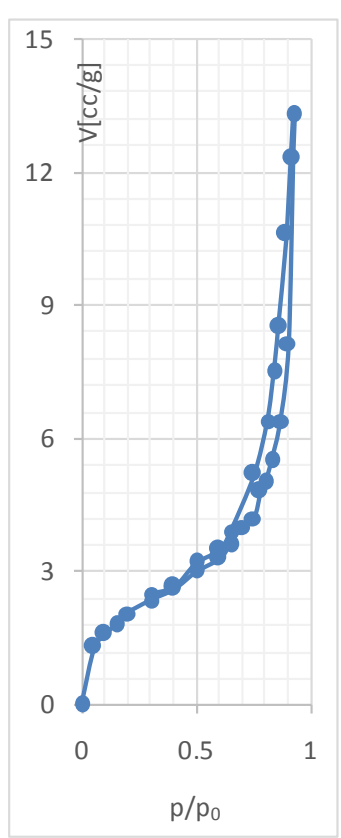

(a)

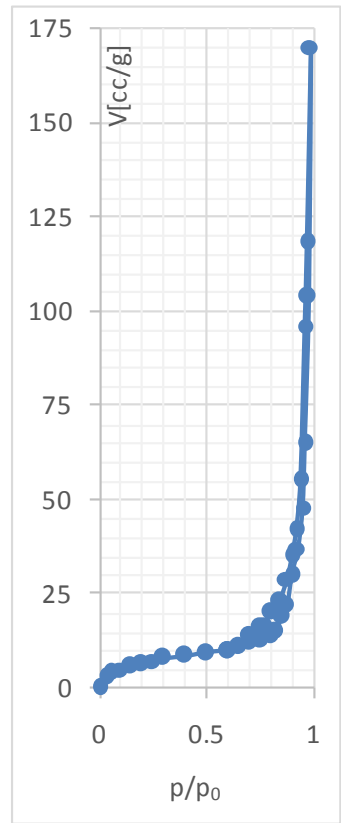

(b)

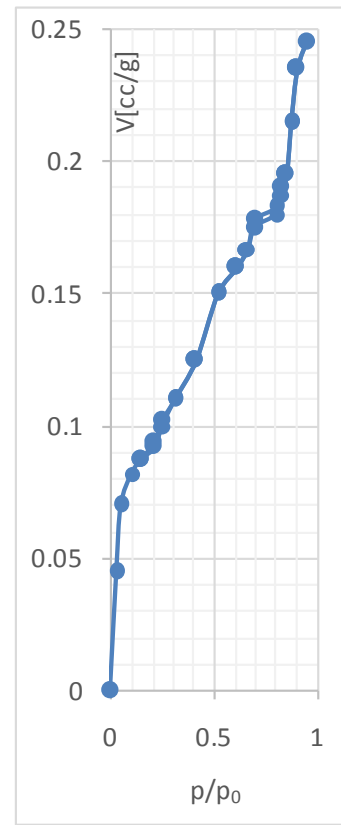

(c)

Figure 5. Isoterms of nitrogen sorption-desorption for lignin samples 1 (a), 3 (b) and 4 (c).

structure or with non-porous structure at the low inner surface but strong interaction adsorbent-adsorbat. There is a plato at the isotherm for hydrolysis lignin that points out to the multilayer adsorption and the occurrence of mesopores in its structure.

Isotherms are well described by BET equation at the interval of $0.05-0.30$ relative pressure of nitrogen that allows calculating the porous structure parameters (Table 5).

As follows from the table data the HL (sample 1 and 2) have higher specific surface 
Table 5. Specific surface square and pores volume along with fuel sorption capacities for lignin samples.

\begin{tabular}{|c|c|c|c|c|c|}
\hline \multirow{2}{*}{ Sample } & \multicolumn{3}{|c|}{ Sorption activity, g/g } & \multicolumn{2}{|c|}{ Surface square in Specific pores } \\
\hline & Diesel fuel & Crude oil & Industrial oil & (BET), $\mathrm{m}^{2} / \mathrm{g}$ & $\mathrm{mm}^{3} / \mathrm{g}$ \\
\hline $\begin{array}{l}\text { "Bobruisk Plant of } \\
\text { Biotechnologies" HL }\end{array}$ & 1.6 & 1.7 & 1.9 & 3.0 & 4.5 \\
\hline $\begin{array}{l}\text { "Rhechitskii } \\
\text { Pilot-Production Plant" HL }\end{array}$ & 1.1 & 1.1 & 1.8 & 7.2 & 16.5 \\
\hline Enzymatic HL & 1.6 & 1.7 & 1.9 & 29.6 & 55.5 \\
\hline Organosolv lignin & 0.5 & 0.5 & 0.6 & 0.45 & 0.50 \\
\hline Sawdust & 2.8 & 3.0 & 4.1 & - & - \\
\hline
\end{tabular}

and pores volume than organosolv lignin (sample 4), but lower than the enzymatic one (sample 3). SEM images demonstrate that the HL particle surface has the complicated relief in contrast to the smooth surface of the organosolv lignin particle (Figure 6).

These morphological and structural features correlate with the lignin samples sorption activity (Table 5).

It is evident from the Table 6 that the higher the drying temperature the lower the surface square and the higher the most probable diameter of the pores and their volume as well. It connects with the influence of the evaporation velocity increase following by the increase of the water vapors pressure that makes the particle structure more crumble [16]. However, it influences on the sorption capacity moderately.

As follows from Table 7 and Table 8, hydrophobized HL sorption activity slightly depends on the samples humidity but the particles' size influences on it.

HL samples has the following characteristics as a sorbent: specific surface $3.7-7.2$ $\mathrm{m}^{2} / \mathrm{g}$ (by $\mathrm{N}_{2}$ ), total pore volume $4.5-16.5 \mathrm{~mm}^{3} / \mathrm{g}$; methylene blue sorption capacity 120 - $170 \mathrm{mg} / \mathrm{g}$; iodine sorption capacity $245-330 \mathrm{mg} / \mathrm{g}$, and oil products sorption capacity $1.2-2.8 \mathrm{~g} / \mathrm{g}$. Compared to other oil sorbents Lignosorb has the lowest sorbent price and the lowest cost of the sorbent required for the sorption of a ton of crude oil (Table 9).

Lignosorb takes up the crude oil and refined products rapidly in the contrast to water that the contact angle study proves (Figure 7).

Hydrophobized HL (Lignosorb) has very good buoyancy in the oil saturated state (1 15 days depending on the weather) and can form solid mass with oil products. It can be easy to remove from the water surface (Figure 8). The ratio of Lignosorb:oil product has to be between $60 \pm 5: 40 \pm 5$ for different systems and environmental conditions.

The attack of the artificial waves on the solidified oil layer was used as a test for its solidity. It was found that the waves up to $5 \mathrm{~cm}$ couldn't destroy the continuity of composite that has been formed on the water mirror with the square $400 \mathrm{~cm}^{2}$ at $2 \mathrm{~mm}$ thickness of the oil layer after the solidification with Lignosorb (Lignosorb:oil wt. ratio $=55: 45)$. To study the influence of water waves the laboratory shaker IKA KS 260 was used. However, the fact that the surface tension strongly decreases after the oil film covers the surface of the water should be taken into account: there is little likely hood of 

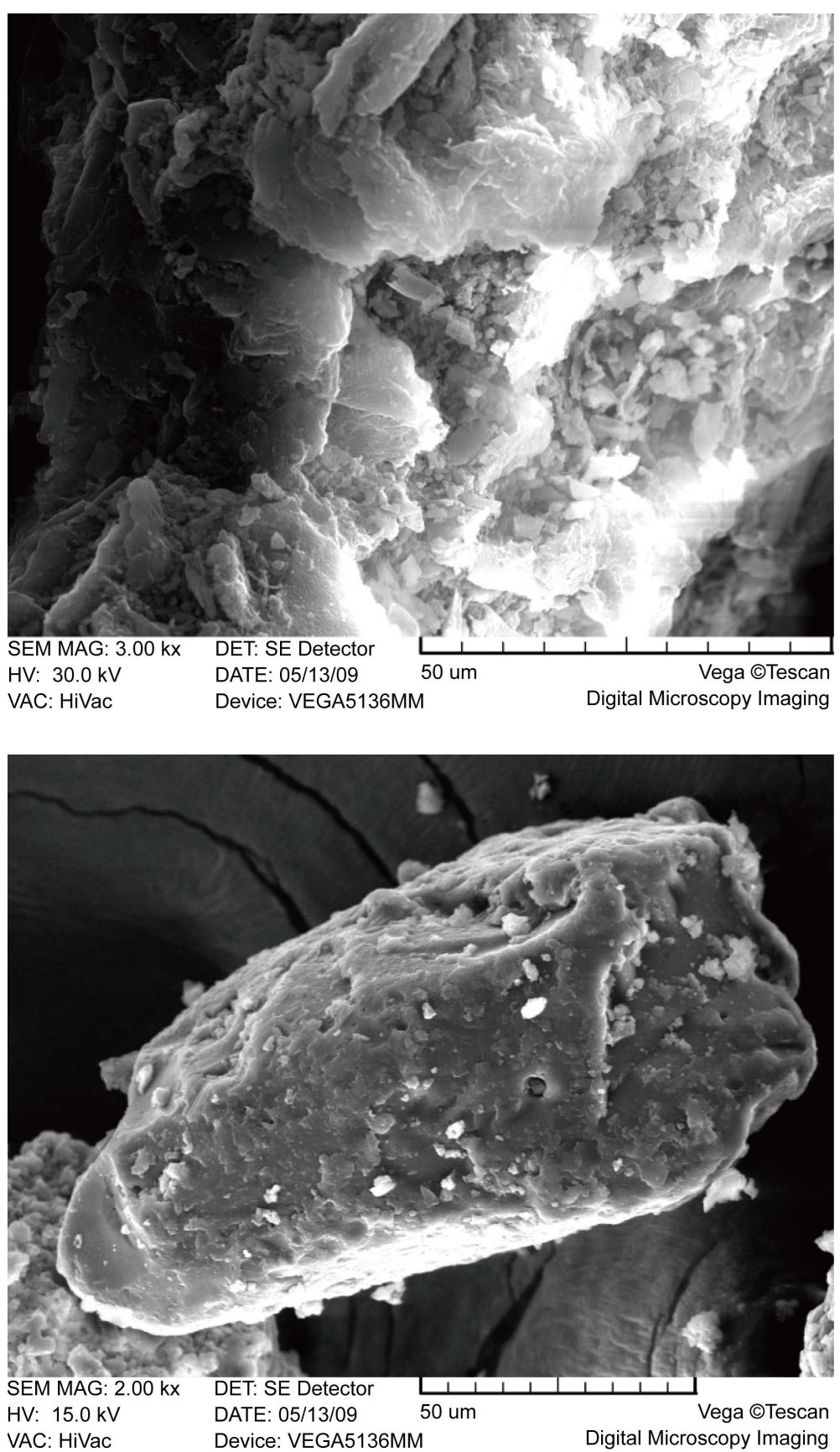

Figure 6. SEM images of lignins' samples: HL (upper) and organosolv (down).

high waves at that water region (Figure 9).

The floating capacity and the strength of the solidified layer of the oil product (where oil product $=$ Diesel Fuel, Industrial Oil and Light Crude Oil) was performed, as according to scheme at Figure 10.

Figure 11 shows that there is certain linear correlation between the solidifying time and the thickness of the fuel layer on the surface of water. Lignosorb was added to achieve the ratio fuel:Lignosorb $=45: 55$. According to Figure 11 diesel fuel gains the 
Table 6. Porous structure and sorption activity of dried $\mathrm{Hl}$ samples.

\begin{tabular}{ccccc}
\hline $\begin{array}{c}\text { Drying } \\
\text { temperature, }{ }^{\circ} \mathrm{C}\end{array}$ & $\begin{array}{c}\text { Integrated surface } \\
\text { square for pores in } \\
\text { terms of nitrogen, } \mathbf{~ m}^{2} / \mathbf{g}\end{array}$ & $\begin{array}{c}\text { Integrated pores } \\
\text { volume, } \mathbf{~ m m}^{3} / \mathbf{g}\end{array}$ & $\begin{array}{c}\text { Pore diameter, } \\
\mathrm{nm}\end{array}$ & $\begin{array}{c}\text { Diesel fuel sorption, } \\
\mathrm{g} / \mathrm{g}\end{array}$ \\
\hline $20-25$ & 13.82 & 75.9 & 21.99 & 1.28 \\
100 & 22.97 & 147.6 & 25.69 & 1.30 \\
150 & 22.28 & 149.0 & 26.76 & 1.31 \\
200 & 22.14 & 155.4 & 28.07 & 1.30 \\
200 (at stirring) & 21.51 & 150.0 & 27.90 & 1.29 \\
\hline
\end{tabular}

Table 7. Influence of HL (sample 1) humidity on bulk density and sorption activity.

\begin{tabular}{ccccc}
\hline \multirow{2}{*}{$\begin{array}{c}\text { Humidity hydrolytic } \\
\text { lignin, \% }\end{array}$} & Bulk density, g/cm & \multicolumn{3}{c}{ Sorption activity, g/g } \\
\cline { 3 - 5 } & & Diesel fuel & Industrial oil & Crude oil \\
\hline 5 & 0.381 & 1.28 & 1.43 & 1.56 \\
10 & 0.392 & 1.27 & 1.33 & 1.48 \\
15 & 0.404 & 1.24 & 1.26 & 1.45 \\
20 & 0.414 & 1.19 & 1.24 & 1.41 \\
& 0.432 & 1.16 & 1.20 & 1.39 \\
\hline
\end{tabular}

Table 8. Sorption activity of fractionated hydrophobized HL (sample 2).

\begin{tabular}{|c|c|c|c|c|c|c|c|}
\hline \multirow{2}{*}{$\begin{array}{l}\text { Lignin } \\
\text { fraction, } \\
\mathrm{mm}\end{array}$} & \multirow{2}{*}{$\begin{array}{c}\text { Fraction } \\
\text { content, \% }\end{array}$} & \multirow[b]{2}{*}{ Humidity, \% } & \multirow{2}{*}{$\begin{array}{l}\text { Bulk density, } \\
\mathrm{kg} / \mathrm{m}^{3}\end{array}$} & \multicolumn{4}{|c|}{ Oil capacity, g/g } \\
\hline & & & & Gasoline & $\begin{array}{c}\text { Diesel } \\
\text { fuel }\end{array}$ & $\begin{array}{l}\text { Oven } \\
\text { fuel }\end{array}$ & $\begin{array}{l}\text { Mazut } \\
\text { M-100 }\end{array}$ \\
\hline$>0.8$ & - & 5.2 & 240 & 1.6 & 1.8 & 1.9 & 2.1 \\
\hline $0.4-0.8$ & 30.5 & 4.0 & 260 & 1.9 & 2.4 & 2.4 & 2.5 \\
\hline $0.25-0.4$ & 23.5 & 4.4 & 270 & 2.1 & 2.2 & 2.2 & 2.8 \\
\hline$<0.25$ & 44.2 & 4.4 & 290 & 1.6 & 1.7 & 2.0 & 1.9 \\
\hline
\end{tabular}

Table 9. Comparison of the sorbents for crude oil.

\begin{tabular}{ccccccc}
\hline Sorbent & $\begin{array}{c}\text { Bulk weight, } \\
\mathrm{kg} / \mathrm{m}^{3}\end{array}$ & $\begin{array}{c}\text { Bouyancy in } \\
\text { oil-saturated } \\
\text { state }\end{array}$ & $\begin{array}{c}\text { Sorption, } \\
\mathrm{g} / \mathrm{g}\end{array}$ & $\begin{array}{c}\text { Sorbent mass for } \\
\text { sorption of crude } \\
\text { oil kg/ton }\end{array}$ & $\begin{array}{c}\text { Sorbent } \\
\text { price, } \$ / \mathrm{kg} \text { sorption of crude } \\
\text { oil, } \$ \text { /ton }\end{array}$ \\
\hline Penoporum & 12 & $5 / 5$ & $\sim 20$ & 50 & $\sim 30$ & $\sim 1500$ \\
Moss & $\sim 70$ & $2 / 5$ & $\sim 10$ & 100 & $\sim 4$ & $\sim 400$ \\
Ecotorf & $\sim 70$ & $1 / 5$ & $\sim 5$ & 200 & $\sim 2$ & $\sim 400$ \\
Lignosorb & 250 & $3 / 5$ & $\sim 3$ & 330 & $\sim 1$ & $\sim 330$ \\
\hline
\end{tabular}




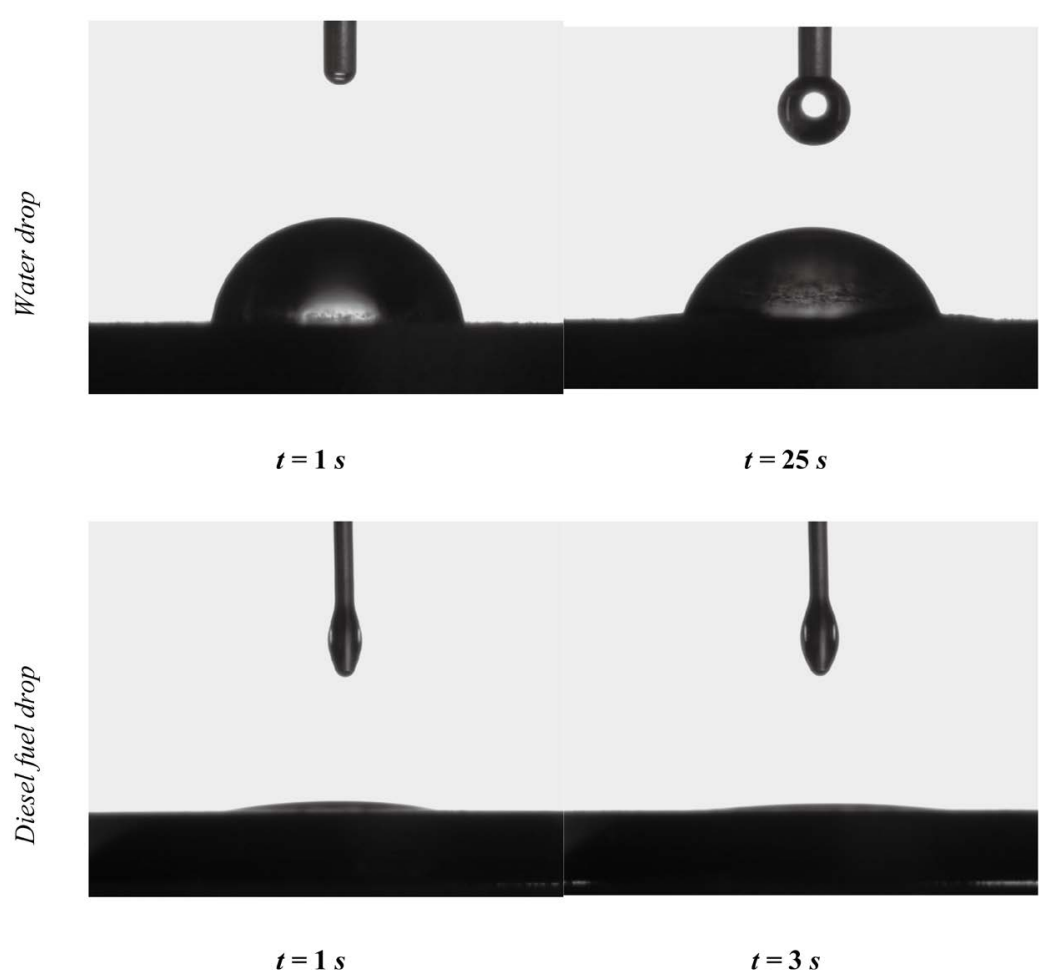

Figure 7. Microphotographs of water and diesel fuel droplets on the surface of the sample 1 of HL.

1

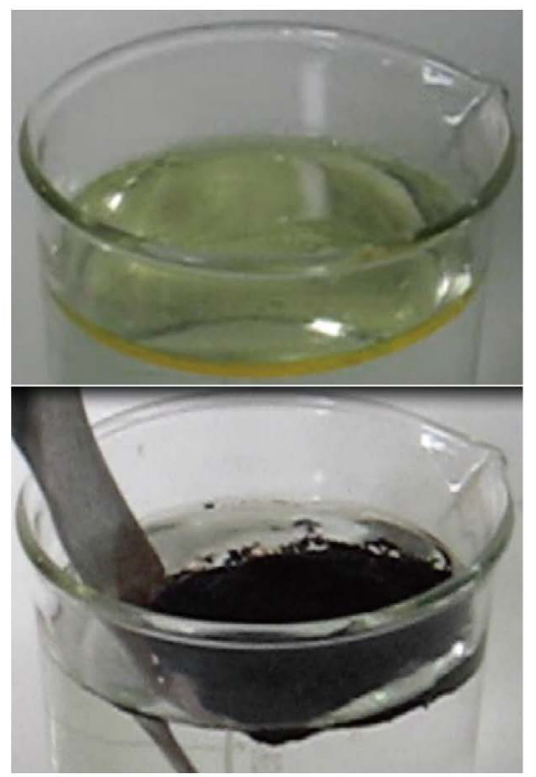

2

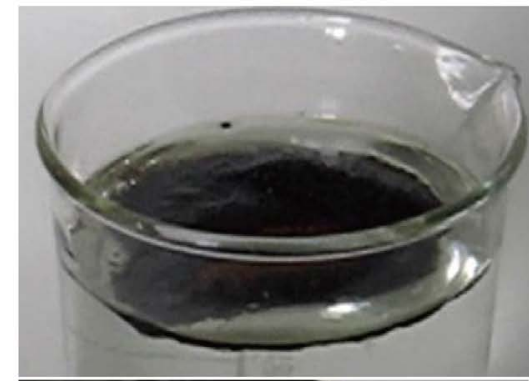

4

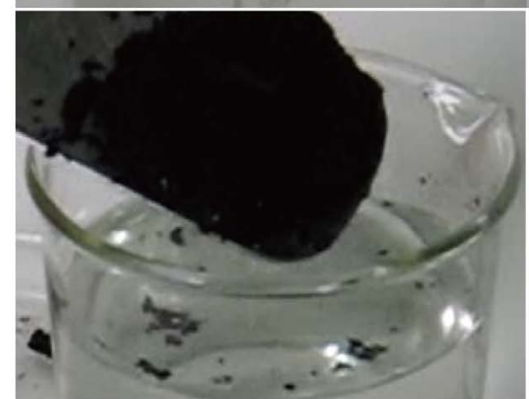

Figure 8. The illustration of the solidifying effect of Lignosorb on the diesel fuel layer.

best-time solidifying ability.

At the ratio of oil product:Lignosorb $=30: 70$ similar data was attempted to be received. However the full solidification was reached only for diesel fuel, whereas for industrial oil full solidification was obtained only for oil thickness $\mathrm{d}=1 \mathrm{~mm}$. The wetting 


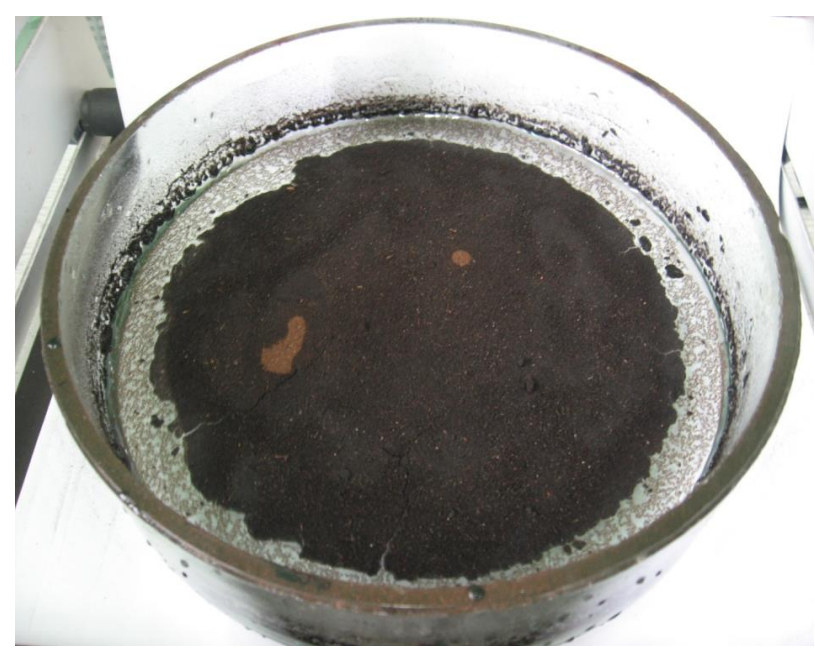

Figure 9. The appearance of the solidified oil layer after waves exposure during 1 hour.

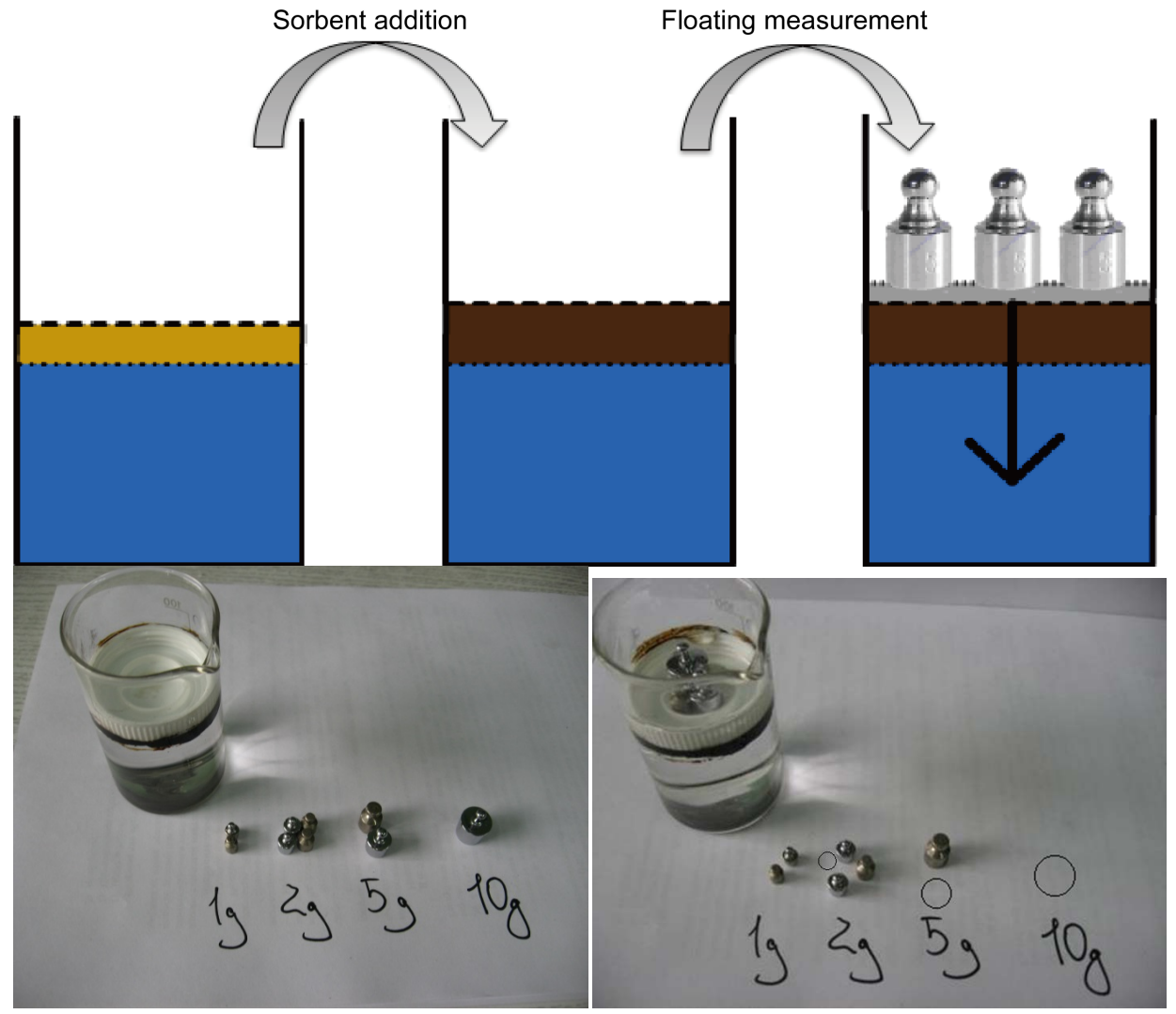

Figure 10. The illustration of the solidifying activity of lignin in reference to light crude oil.

of Lignosorb by crude oil in the whole mass of lignin has not been reached nor with any oil thickness. As the redistribution of diesel fuel takes place at wide range of ratios, extra experiments were brought out. Figure 12 illustrates the comparison plots of diesel fuel's times of solidification versus components ratio for different layer's thickness on the water surface. 


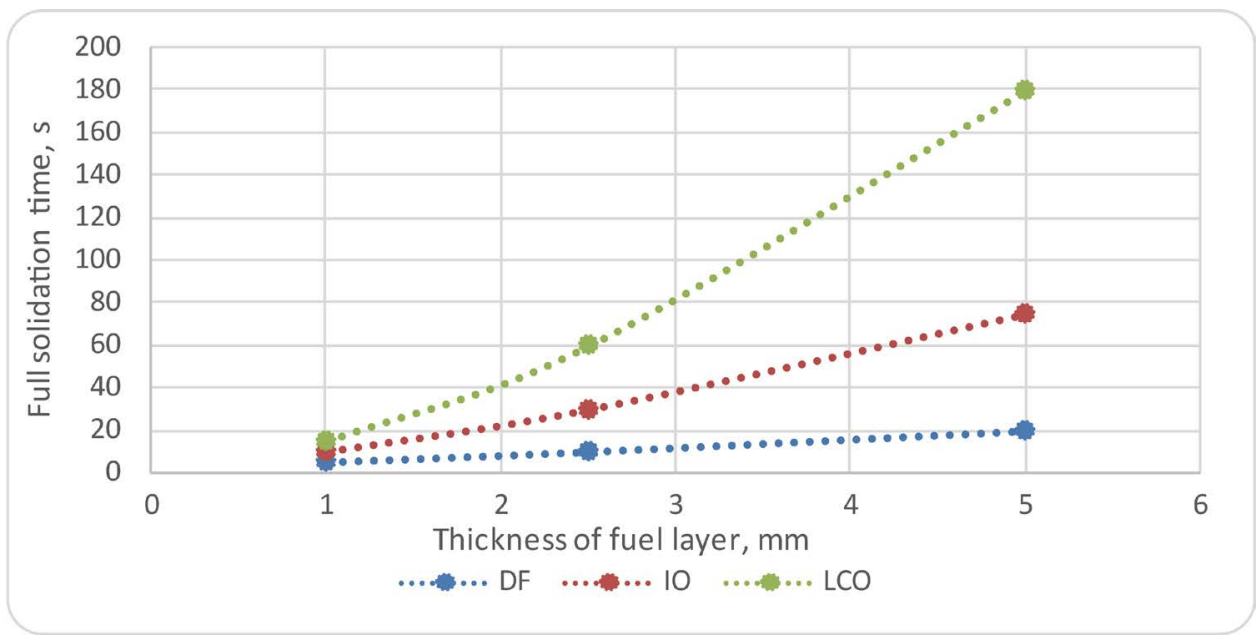

Figure 11. The solidification time of different oil product-Lignosorb composites with their ratio equals to $45: 55$ versuslayer's thickness.

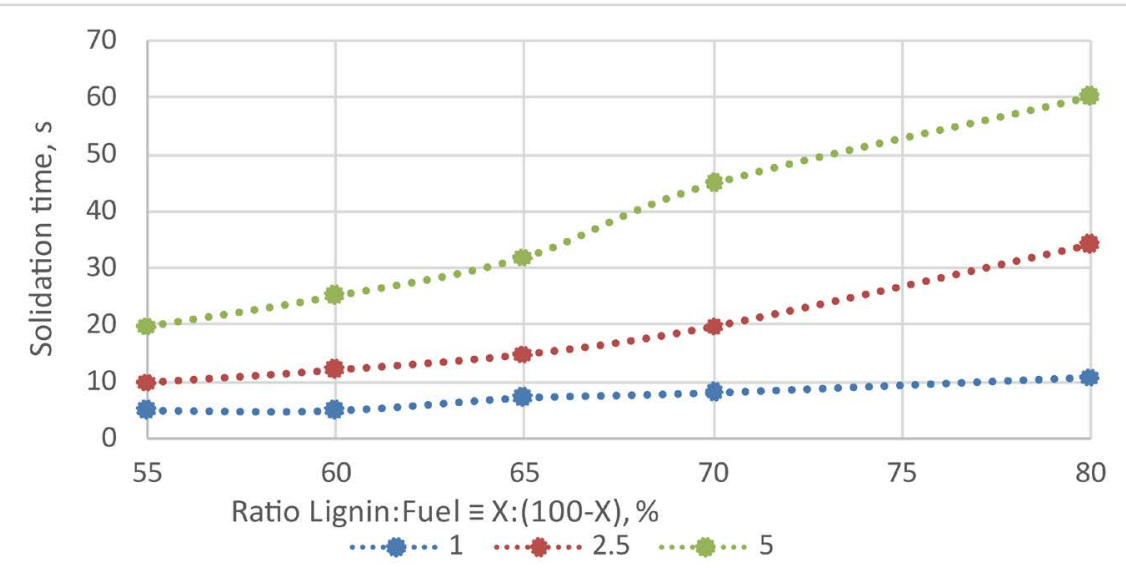

Figure 12. The solidification time of diesel fuel-Lignosorb compositesfor different layer's thickness versus Lignosorb content.

\subsection{Composite Fuel Processing and Properties}

According to the proposed technology, the composite fuel can be produced in the form of granules or pellets. The technology developed and widely exploited for the production of fuel pellets from wood- and plant-based biomass was used for processing of hydrophobized HL due to the ability of the latter to the transition in plastic state under influence of high pressure. Pressure is not used in the case of granulated fuel production. Oil product-Lignosorb mixture can be formed at the oil spill removal upon lignin pouring on the surface of oil or by mixing of oil products waste with lignin in any storage capacity.

Firm pellets have been produced even in the laboratory scale by the hydraulic press. Their strength at the horizontal direction was $0.38 \mathrm{MPa}$ and $1.5 \mathrm{MPa}$ at the vertical one. There is less reported on tests of full-scale combustion of lignin. Google gave only 48 hits for the term "combustion of lignin". That should be compared with 3700 hits for 
"combustion of wood". Only few examples: lignin is burned either as powder or as slurry (mixed with oil and water). The average composition of the slurry was $40 \%$ lignin, $41 \%$ water and $19 \%$ oil. A surfactant is added too $(0.1 \%-0.2 \%)$. The tests showed that the temperature and the calcinations fields with powder or slurry were similar. Studies done at Energy \& Environmental Research Centre (EERC), USA where lignin is used as additive to coal [17]. With its characteristics of high dispersion and fluidity, the fine particulate of lignin, down to nanometers range, through adoption of an innovative activation technology can be evenly mixed with diesel oil to form a kind of quasi-liquid fuel of a state in between liquid and solid, and thus become a partial substitute for diesel oil [18].

As indicated by the thermal analysis data, composite fuel Lignosorb-industrial oil is characterized by the more complete combustion of lignin. It is obvious from Figure 13

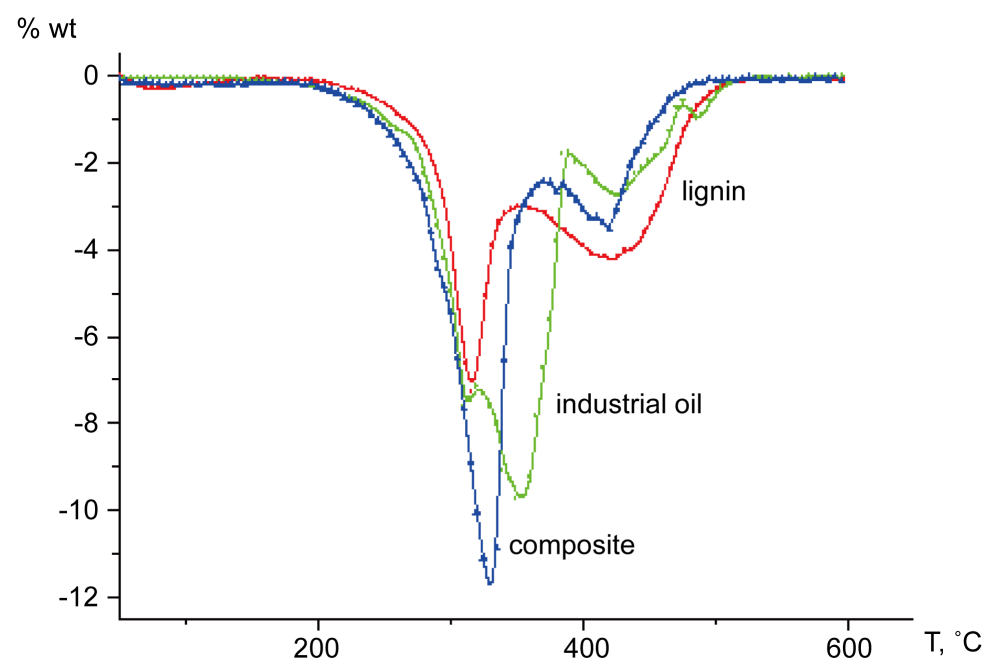

(a)

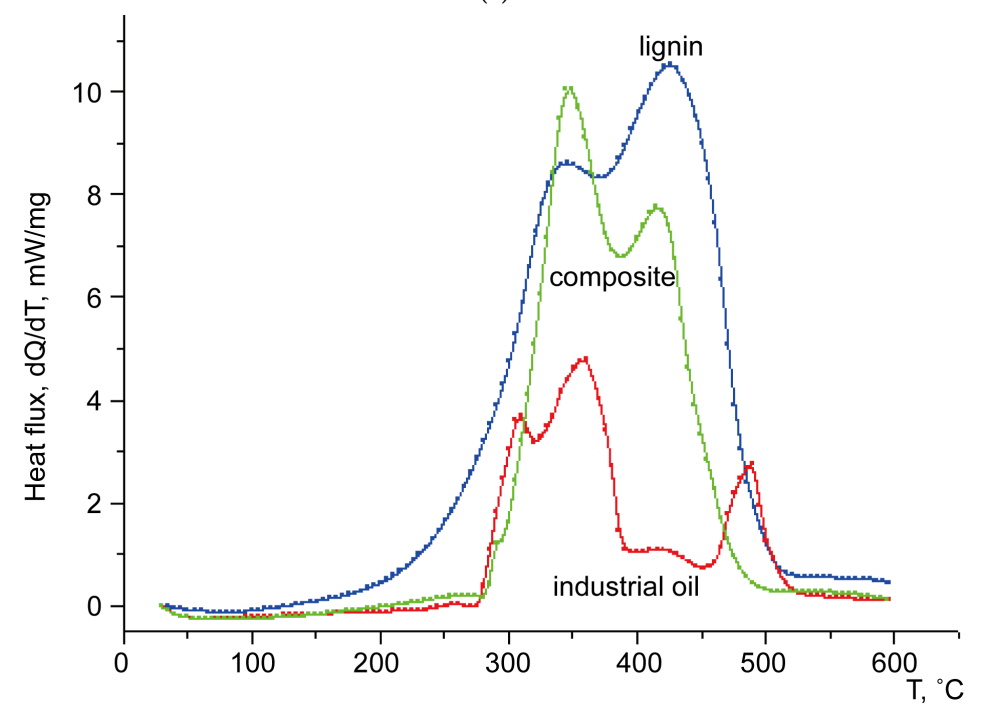

(b)

Figure 13. DTG (a) and DSC (b) curves for the samples of Lignosorb, industrial oil and composite fuel. 
that lignin thermally decompose over a broad temperature range. DTG curve of lignin has three peaks at $78^{\circ} \mathrm{C}, 316^{\circ} \mathrm{C}$ and $421^{\circ} \mathrm{C}$. Peak at $78^{\circ} \mathrm{C}$ is related to the loss of lignin moisture. Decomposition of lignin has two stage and begins at $280^{\circ} \mathrm{C}$. The main process occurring around $400^{\circ} \mathrm{C}$ with the formation of aromatic hydrocarbons, phenolics, hydrohyphenolics and quaiacyl/syringyl-type compounds, most products having phenolic -OH groups [19]. The residue of mass is $19.07 \%$. The mixture of lignin:Industrial oil $=1: 1$ differs in the loss of mass at the first stage: it composes up to $70 \%$ unlike $30 \%$ for the lignin. The residue of mass becomes $8.74 \%$ in this case and it decreases up to $5.39 \%$ for the mixture of lignin:industrial oil with the composition 3:1 that indicates the combustion in larger degree.

Table 10 shows the highest calorific values (HCV) of different types of composite fuel for the conventional solid fuels including the pellets of the hydrophobized lignin itself (Lignosorb).

The parameters regulated by ASTM, DIN, ONORM, CN/TS 335 international standards: elemental composition $(\mathrm{C}, \mathrm{H}, \mathrm{N})$ and calorific value were determined at the laboratory of Lignin chemistry at the Latvian State Institute of Wood Chemistry (Riga, Latvia). The comparison of the experimental values and the calculated ones was done and the results are presented in Table 11.

Table 10. The highest calorific values for different types of the solid fuels.

\begin{tabular}{cc}
\hline Sample & Gross calorific value, $\mathbf{M J} / \mathbf{k g}$ \\
\hline Lignosorb + crude oil & 38.8 \\
Lignosorb + diesel fuel & 32.3 \\
Llignosorb + industrial oil & 32.1 \\
Lignosorb & 22.7 \\
Brown coal & 10.5 \\
Black coal & 20.9 \\
Anthracite & 26.8 \\
\hline
\end{tabular}

Table 11. Characteristics of pelleted fuel humidity and calorific value*.

\begin{tabular}{cccccc}
\hline Sample & Humidity,\% & $\begin{array}{c}\text { Calorific value using the } \\
\text { working mass (experiment), } \\
\text { MJ/kg }\end{array}$ & $\begin{array}{c}\text { Calorific value calculated } \\
\text { using the experimental mass } \\
\text { calculation according to e } \\
\text { quation, }{ }^{*} \text { MJ/kg, }\end{array}$ \\
\cline { 3 - 6 } & 7.9 & 17.9 & 16.5 & 18.3 & LCV \\
\hline $\begin{array}{c}\text { Wood granules } \\
\text { Lignin }\end{array}$ & 11 & 18.8 & 17.4 & 17.3 & 16.9 \\
Lignooil & 7.4 & 22.6 & 21.2 & 17.9 & 16.5 \\
$\begin{array}{c}\text { (lignin + oil) } \\
\text { Determination } \\
\text { method }\end{array}$ & CEN/TS 14774-3 & CEN/TS 14918 & - & CEN/TS 14918 & - \\
\hline
\end{tabular}


For the calculation of the highest calorific value (HCV) the following equation [20] was used:

$$
H C V=3.55 \cdot C^{2}-232 \cdot C-2230 \cdot H+51.2 \cdot C \cdot H+131 \cdot N+20600,
$$

where HVC-highest calorific value, $\mathrm{kJ} / \mathrm{kg}$;

C, $\mathrm{H}, \mathrm{N}$-the content of the elements in the sample, $\%$.

Lowest calorific value was calculated as well by the following equation:

$$
L C V=H C V-0.0251 \cdot(9 H+W)
$$

where $H$-content of organic hydrogen, \%;

$W$-relative humidity, \%;

2510-specific water evaporation heat, $\mathrm{kJ} / \mathrm{kg}$.

As follows from the data of Table 11, carbon content per dry fuel mass without ash is higher in composite fuels than in wood. The reason is the removal of the part of hydrocarbons during the pyrolysis.

The experimental data of HCV for Lignooil are $26 \%$ higher than the calculated ones. Absence of the pre-drying before testing may be suggested as the reason of that.

The process of burning of the fuel pellets was conducted by the original unit with the camera of the gasification and the camera of burning of volatile products pyrolysis/ biomass gasification (Figure 14). Each camera has their own water-cooled heat-exchange unit with two thermopairs connected to the electronic plates of PC for input and output stream of the water. The measurements of water stream temperature and the calculation of the absorption heat quantity was carried out in the on-line regime (1 count per second). The propane burner with the capacity of $1.2 \mathrm{KW}$ was used for the
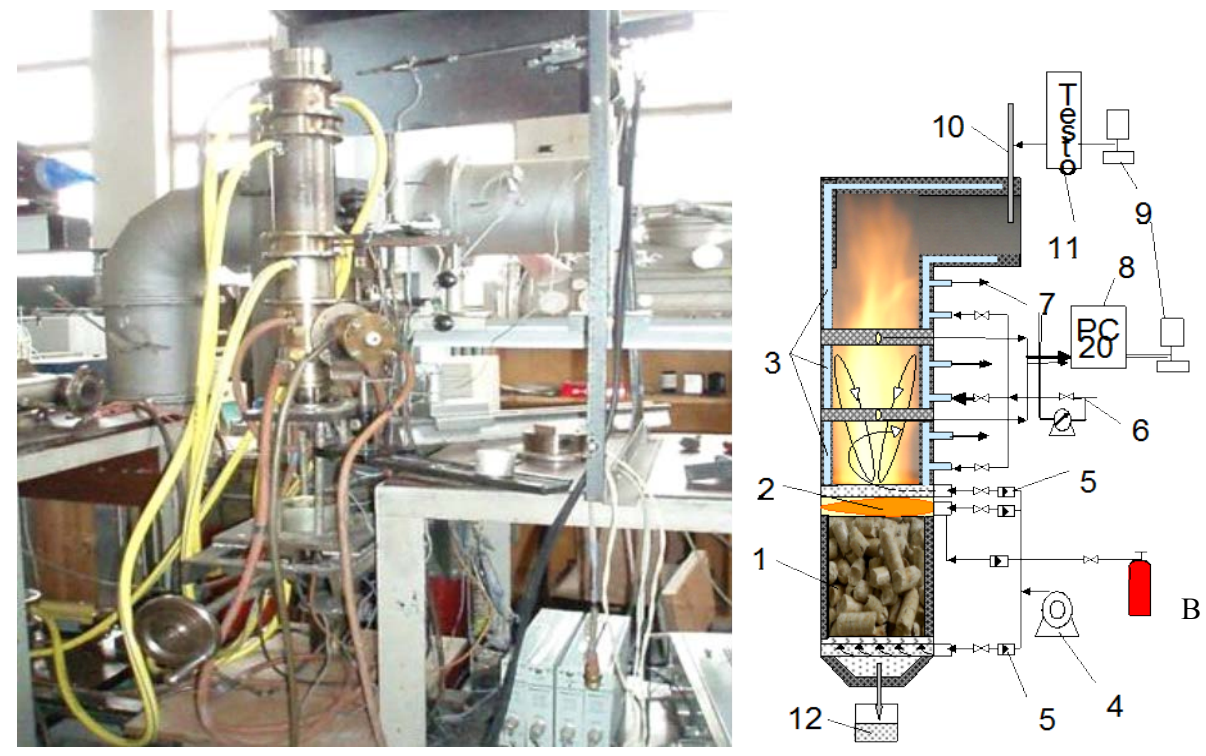

Figure 14. Main view of the unit for the estimation of biomass burning (a) and its principle scheme (B): 1-gasifier, 2-propane burner, 3-heat-exchanger jacket of the burning camera, 4 5 -system of air supply, 6 - 7-delivery pipe for water supply, 8-electronic plate, 9-PC, 10 11-effluent gases analyzer Testo 350XL, 12-ash collector. 
initiation of the burning. The content of $\mathrm{O}_{2}, \mathrm{CO}_{2}, \mathrm{CO}, \mathrm{NO}_{\mathrm{x}}$ in the combustion products and temperature of the exhaust gases screen were hold by the analyzer of effluent gases Testo 350XL in the on-line regime (1 data point per second).

Three stages of the burning process: stage of inflammation, stage of stable burning and stage of smoldering have been studied. Lignin burning has more longstanding inflammation stage, more short burning stage and more longstanding phase of smoldering. The stage of inflammation was determined as an interval of time between the beginning of the propane flame contact with biomass and the moment of reduce of oxygen content in the burning products from $20.9 \%$ to $10.5 \%$. It corresponds to the excess of air $\alpha=2.0$. The stage of stable burning was determined as the interval of time when $\alpha$ $\leq 2$. The stage of smoldering was determined as the time interval between the second stage and the moment when the oxygen content in the burning products reaches $20.9 \%$.

Figure 15(a) shows that the time of the inflammation of composite fuel is reduced with the including of the oil products into the composition of the lignin pellets. It is lower than the corresponding value of the wood. Stable burning stage time is increased and the stage of smoldering is reduced for composite fuel.

However, the time of smoldering in the absolute values and in the percentage ratio exceeds the same one for wood (Table 12). Average burning velocity (velocity of mass loss) has increased in $12 \%$ according to the Lignin pellets but it was lower than for wood pellets. Clearly, the oil product burns down with rather high velocity but at later time the lignin burning runs with the characteristic species of the elongated smoldering stage like lignin itself.

The amount of $\mathrm{CO}_{2}$ in the exhaust gases has been shown to reduce for Lignin pellets as compared to wood and Lignooil pellets. As this takes place, the $\mathrm{CO}$ amount was the lowest (Table 13) as well. This parameter was higher for combine fuel pellets (Figure 15). One conceivable reason for higher concentration of $\mathrm{CO}_{2}$ is the large amount of the volatile pyrolysis products coming to the zone of burning in the covered period of time. The highest average temperature in the active burning zone also proves it.

Owing to the high calorific value, special features of the burning stages composite solid fuel based on lignin and waste of oil products are the perspective kinds of the solid fuels.

\subsection{Rheological Properties of Lignin-Oil Products Dispersions}

Rheological behavior of lignin-oil product dispersion was under study because of the combine fuel pellets production process includes the stage of lignin-oil products mixturing. Rheological properties of hydrolytic hydrophobized lignin are little studied [21]. Only a few works are known for colloidal-chemical properties of technical lignin in water dispersions. In this study the behavior of lignin-crude oil and different refined products dispersions was estimated in the wide range of the composition. As follows from Figure 16 the flow curves and viscosity rheograms for dilute lignin-industrial oil dispersions are agreed almost exactly up to the lignin content of $15 \%$ (mass) when being deformed by increase and consequent decrease of the shear rate. The following increasing of lignin content results in viscosity increase and the appearance of the hysteresis loop on the flow curves and viscosity rheograms as well. A loop test was to 


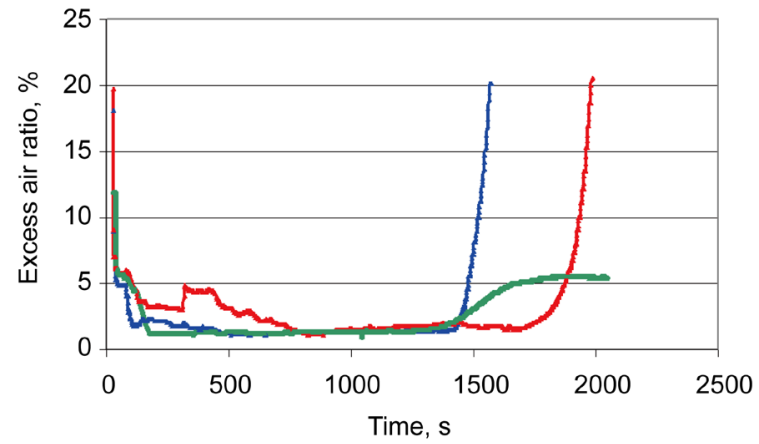

(a)

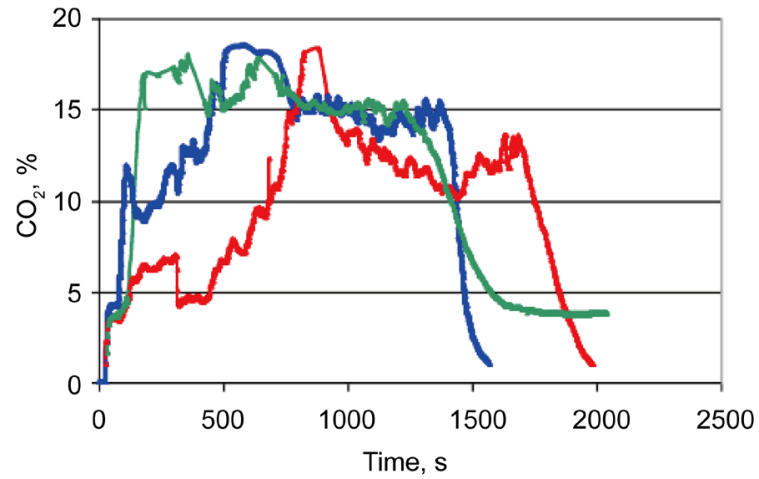

(b)

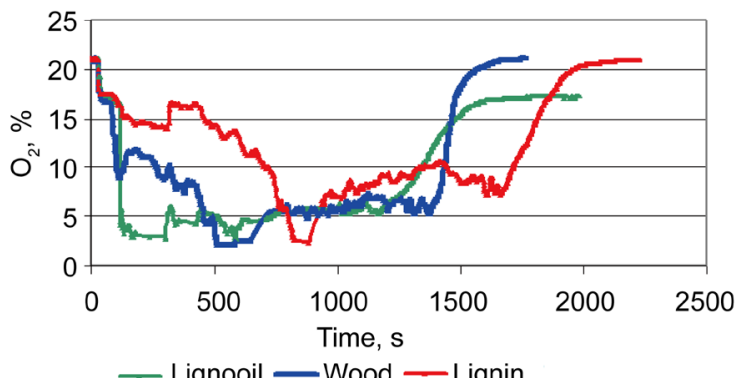

(c)

Figure 15. Variation of the oxygen content in the products of burning and the coefficient $\alpha$ of air excess (a) and changing of the composition of fuel gases for the pelleted fuel combustion $\left(\mathrm{CO}_{2}-\right.$ b, $\left.\mathrm{O}_{2}-\mathrm{c}\right)$.

Table 12. Duration of the different burning stages and the average velocity of the mass loss for fuel pellets.

\begin{tabular}{cccccccc}
\hline & \multicolumn{2}{c}{ Inflammation } & \multicolumn{2}{c}{ Stable burning* } & \multicolumn{2}{c}{ Smoldering* $^{*}$ Sample } & \multicolumn{2}{c}{ duration } & \multicolumn{2}{c}{ duration } & \multicolumn{2}{c}{ duration } & $\begin{array}{c}\text { Velocity of the } \\
\text { mass loss, g/min ** }\end{array}$ \\
\cline { 2 - 7 } & seconds & $\% *$ & seconds & $\%^{*}$ & seconds & $\%^{*}$ & \\
\hline Wood & 256 & 15 & 1240 & 73 & 274 & 12 & 7.2 \\
Lignin & 687 & 31 & 1053 & 48 & 467 & 21 & 5.3 \\
$\begin{array}{c}\text { Lignooil } \\
\text { (lignin + oil) }\end{array}$ & 183 & 10 & 1224 & 69 & 362 & 21 & 6.0 \\
\hline
\end{tabular}

* - percentages of the total duration of the process; ${ }^{* *}$ - per dried ashless mass of the fuel. 
Table 13. Average characteristics of the composition of combustion gases, of the fuel gases and their temperature (Tg) and the temperature in the zone of stable combustion (Tc) of the test pellets.

\begin{tabular}{ccccccccc}
\hline \multirow{2}{*}{ Pellet sample } & \multicolumn{2}{c}{ Air consumption, g/K } & \multicolumn{2}{c}{ Average concentration } & \multirow{2}{*}{$\mathrm{Tc}, \mathrm{K}$} & $\mathrm{Tg}, \mathrm{K}$ & $\boldsymbol{\alpha}$ \\
\cline { 2 - 5 } & primary & secondary & $\mathrm{O}_{2}, \%$ & $\mathrm{CO}, \mathrm{ppm}$ & & & \\
\hline Wood & 0.61 & 0.94 & 6.45 & 112.0 & 1326 & 781 & 1.4 \\
Lignin & 0.77 & 1.27 & 8.45 & 59.5 & 1316 & 727 & 1.6 \\
Lignooil & 0.77 & 1.27 & 5.60 & 89.7 & 1385 & 796 & 1.3 \\
\hline
\end{tabular}
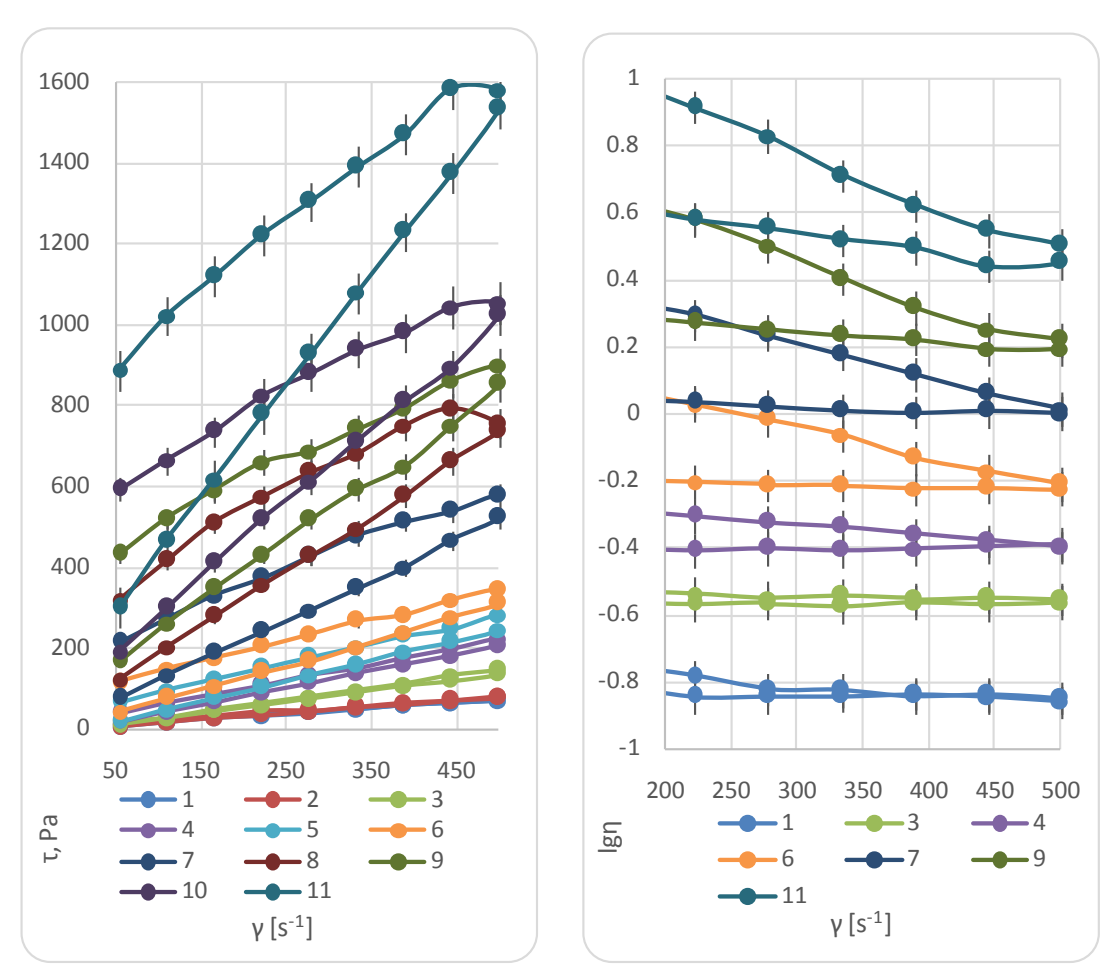

Figure 16. Flow curves for the lignin: industrial oil dispersions at different lignin contents: for $\mathrm{n}$ $<10$. where $\mathrm{n}$ is the number of the curve, lignin:fuel ratio can be find from $[(\mathrm{n}-1) * 0.05]:[1.05-$ $0.05 n$ ]; curve 10 represents the ratio 42:58; curve 11 -the ratio 44:56.

linearly increase shear rate from minimum $\left(50 \mathrm{~s}^{-1}\right)$ to a maximum value $\left(500 \mathrm{~s}^{-1}\right)$, and then to return with the same rate to $50 \mathrm{~s}^{-1}$. The more the lignin content the larger the loop square. Hysteresis loop test is used for the thixotropy estimation.

There are some definitions in the history of thixotropy in literature [22]. According to one of them thixotropy is a viscosity decrease under shearing, followed by a gradual recovery when the shear is removed. The time is the key factor in thixotropy, as if the viscosity reduces and returns after shearing immediately it means that the system has no need in relaxation time and the studied material is called "shear thinning", not thixotropic. Otherwise, the process of relaxation takes some time, and there is a gap before the system returns to its initial state. The larger the area of the hysteresis loop the 
stronger the system is destroyed, so the larger thixotropy it has.

Loops due to the fact that after mechanical destruction the dispersion structure is restored thixotropically more slowly with time, and in the given regime of deformation the coagulation contacts between the dispersion structure elements have no time to be restored completely. In this case, the degree of thixotropy increases with increasing the concentration of lignin in the dispersion, which is correlated with the hysteresis on the viscosity rheograms. Dispersions have been found to lose the flow capacity to become solid at different components ratio depending on the lignin and oil products characteristics, and their concentration. But there is the interruption of discontinuity in concentration profile of the loops square for some systems near the area of solidification.

Hysteresis loops on flow curves for crude oil and different oil products-lignin suspensions at one and the same component ratio in the narrow interval of the oil content are shown in Figure 17.

According to the obtained data, it was noticed that dispersions of lignin in the industrial oil proved to be the most structured largely due to initial high viscosity of industrial oil that prevents quick structural disordering (Table 14).

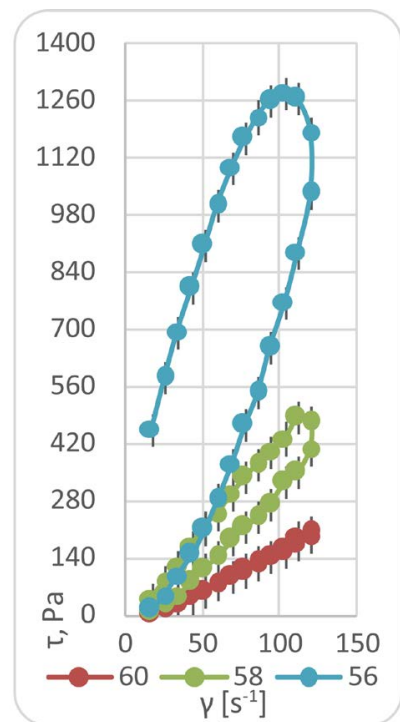

Diesel Fuel

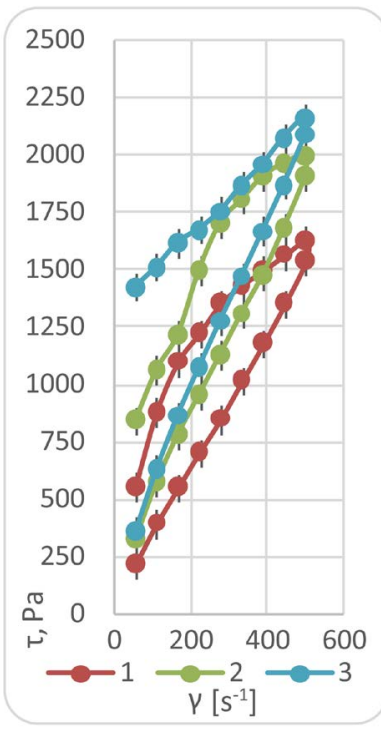

Industrial Oil

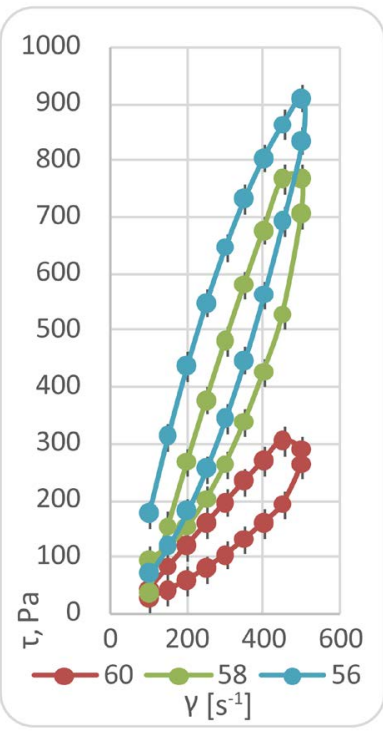

Light Crude Oil

Figure 17. Hysteresis loops for flow curves of lignin dispersions in diesel fuel (a), industrial oil (b) and light crude oil (c) at oil product percentage: $60 \%(1), 58 \%(2), 56 \%(3)$.

Table 14. Hysteresis loop square ratio for different oil product-lignin dispersions at oil product percentage: $60 \%(1), 58 \%(2), 56 \%(3)$.

\begin{tabular}{cccc}
\hline $\mathbf{n}$ & Diesel Fuel & Industrial Oil & Light Crude Oil \\
\hline 1 & 0.05 & 0.71 & 0.58 \\
2 & 0.17 & 0.75 & 0.70 \\
3 & 1.00 & 1.00 & 1.00 \\
\hline
\end{tabular}


For crude oil-lignin systems [20] having been studied before we assumed that due to the action of the capillary forces a solid bound dispersed systems, a quasi-gel, is formed at definite components ratio. Figure 18 illustrates the solidification of the lignin-diesel fuel dispersion: separate particles turn into the system with restricted particles. The system's integrity is probably determined by the appearance of a capillary contracting force between lignin-swollen particles with occluded oil. This force arises at

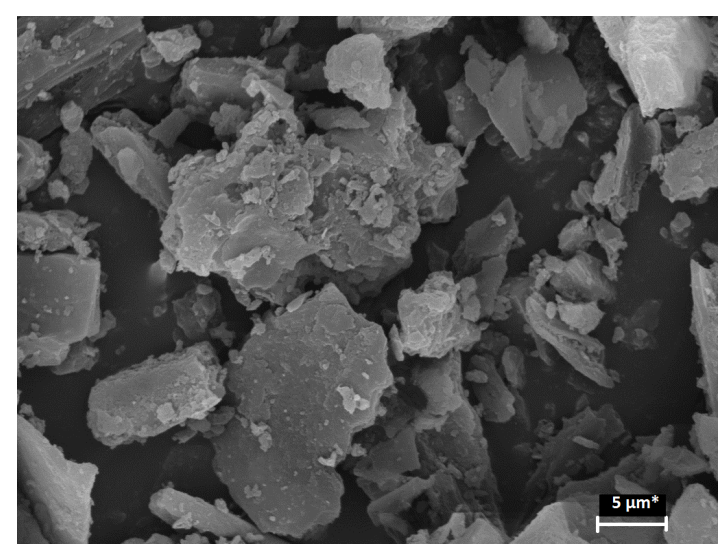

(a)

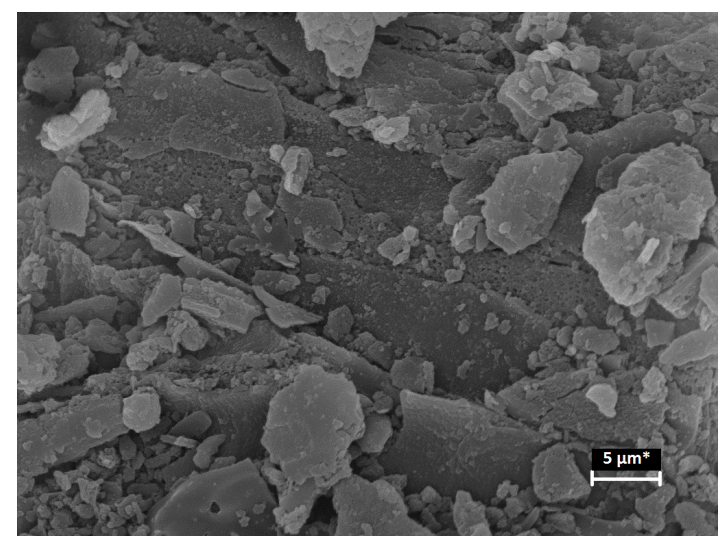

(b)

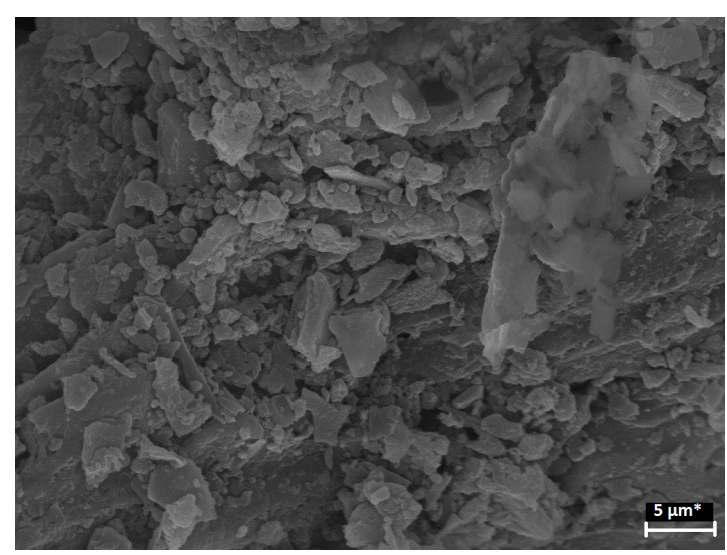

(c)

Figure 18. SEM of the lignin: diesel fuel dispersions: (a) - 100:0; (b) -66:34; (c) - 50:50. 
the definite amount of the liquid oil between particles that provide meniscus curvature in the form of cup. As a result, of the force action, the particles are attracted to each other and the structured system is formed. This makes it possible to remove easily and practically without loss the oil-saturated sorbent from the surface of the water.

Particle size influence on the rheology behavior of the dispersion was also studied. It was found that it is not the size that has influence on the rheological behavior, but the distribution and more specifically the width of the peak of the size distribution. Figure 19 demonstrates the particle size distribution curves for fractions of hydrophobized HL (sample 2).

It can be seen from Figure 20 that the hysteresis loop appears at the definite ratio oil -lignin. The criterion to determine the content of oil $\left(\mathrm{w}_{1}\right)$, when the hysteresis loop is clearly expressed, was the area of the loop (the last content, before $S_{\text {loop }} \geq 20000$ ). At the same time $\mathrm{w}_{2}$ represents the maximum of lignin content in oil product -lignin dispersion (Table 15) when it able to flow.

The data for sorption capacity of lignin fractions are shown in Table 16.

The output of Table 16 data is the following: almost all oil products and crude oil can be absorbed by HHL; there is no simple correlation between sorption capacity and oil product viscosity, density or surface tension and the same to solidifying activity. Nevertheless, for fuels, that have high values of viscosity and surface tension (crude oil) the sorption capacity would be expected the largest, so the higher the values, the larger the sorption capacity. As for benzene (low surface tension, low viscosity) the smallest capacity has been determined. For fuels that have either high viscosity or high surface tension average sorption capacity between crude oil and benzene is observed. Further research are needed for establishing the optimal conditions for oil polluted systems treatment and regime of the effective combustion.

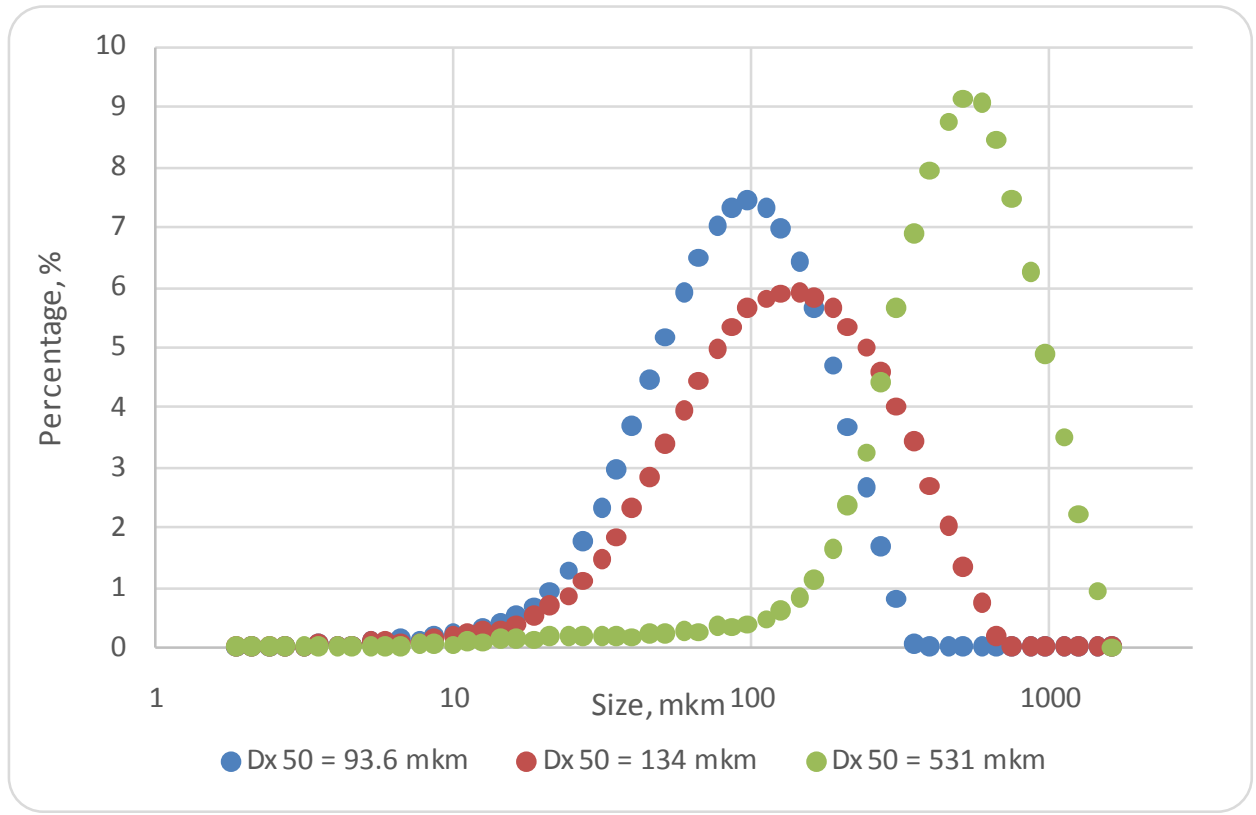

Figure 19. Particle size distribution curves for the fractions of the HHL sample 2. 

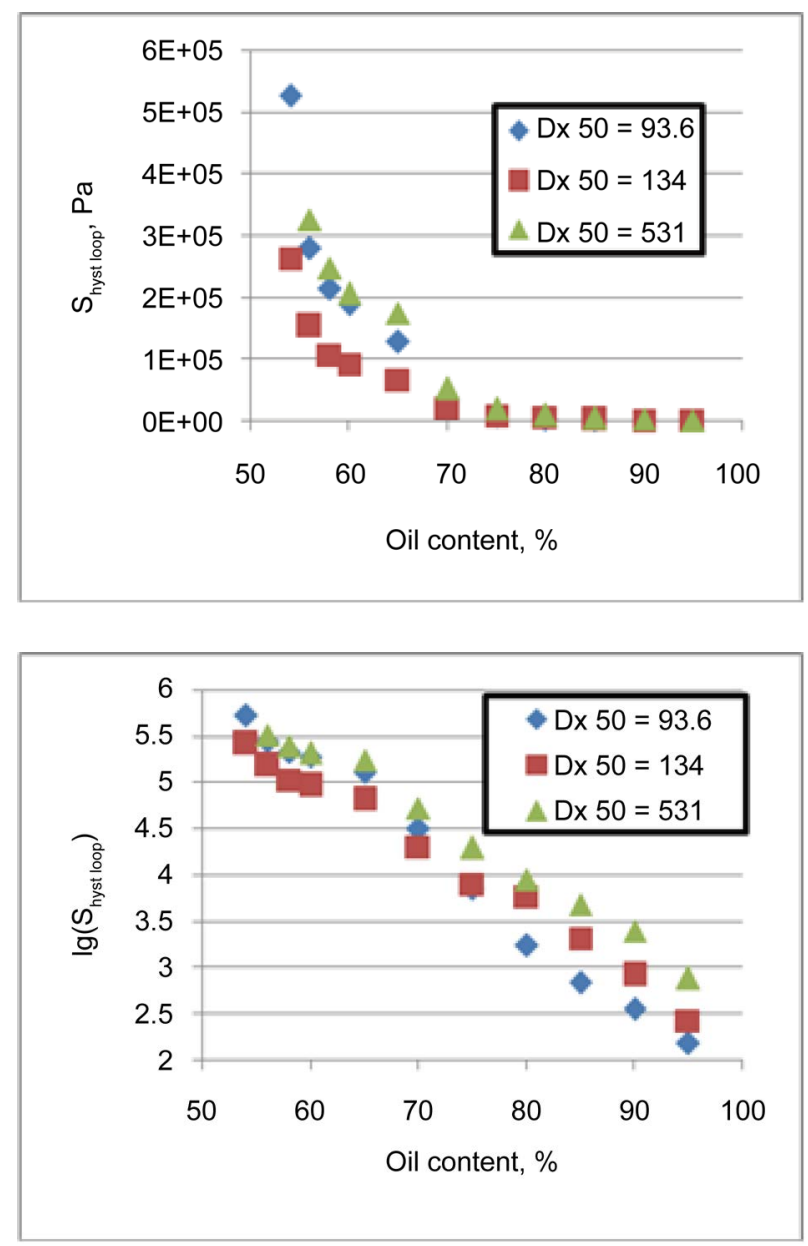

Figure 20. Hysteresis loop square via oil percentage for fractionate lignin-industrial oil dispersions.

Table 15. Oil content in fractioned lignin-industrial oil dispersion that corresponds to the hysteresis loop appearance and dispersion solidification.

\begin{tabular}{|c|c|c|c|c|}
\hline & & Dx $50=93.6$ fraction & Dx $50=134$ fraction & Dx $50=531$ fraction \\
\hline \multirow{2}{*}{ Oil percentage } & w1 & $75 \%$ & $70 \%$ & $75 \%$ \\
\hline & w2 & $54 \%$ & $54 \%$ & $56 \%$ \\
\hline
\end{tabular}

\section{Conclusions}

Nowadays, there are different technologies and means for the ecological protection against oil pollution in the world, depending of the kind, the composition, and the location of the pollution. The development of oil response methods depends on the national features of the oil pollution issues but in any case, it has to provide net environmental benefits. Each response method has its own advantages and disadvantages. But as a strategy, the use of waste product for oil waste removal looks very attractive. Hydriphobized HL (Lignosorb) is one of these kinds of sorbents. In spite of the fact that there are a few examples of the studies of technical lignin using as a sorbents, almost all 
Table 16. Characteristics for oil products, fractionate lignin and their mixtures.

\begin{tabular}{|c|c|c|c|c|c|c|c|}
\hline & \multirow[b]{2}{*}{$\begin{array}{l}\text { Density, } \\
\mathrm{g} / \mathrm{cm}^{3}\end{array}$} & \multirow[b]{2}{*}{$\begin{array}{c}\text { Surface } \\
\text { Tension, } \\
\sigma \cdot 10^{3} \mathrm{~N} / \mathrm{m}\end{array}$} & \multirow[b]{2}{*}{$\begin{array}{l}\text { Viscosity, } \\
\text { mPa.s }\end{array}$} & \multicolumn{3}{|c|}{ Sorbtion Capacity, g/g } & \multirow[b]{2}{*}{$\begin{array}{c}\text { Wstructure, \% } \\
\text { lignin }\end{array}$} \\
\hline & & & & $\begin{array}{c}\text { Particle size } \\
\text { (Mode) } \\
\text { mkm }\end{array}$ & Capacity & Average & \\
\hline \multirow{3}{*}{$\begin{array}{l}\text { CrudeOil } \\
\text { (light) }\end{array}$} & & & & 531 & 1.76 & & \\
\hline & 0.81 & 28.60 & 134.97 & 134 & 1.75 & 1.68 & 44.50 \\
\hline & & & & 93.6 & 1.53 & & \\
\hline \multirow{3}{*}{ Diesel Fuel } & & & & 531 & 1.67 & & \\
\hline & 0.8 & 30.80 & 5.90 & 134 & 1.55 & 1.56 & 41.50 \\
\hline & & & & 93.6 & 1.45 & & \\
\hline \multirow{3}{*}{ IndustrialOil } & & & & 531 & 1.58 & & \\
\hline & 0.83 & 27.75 & 319.01 & 134 & 1.52 & 1.55 & 43.00 \\
\hline & & & & 93.6 & 1.55 & & \\
\hline \multirow{3}{*}{ Benzine } & & & & 531 & 1.47 & & \\
\hline & 0.78 & 21.15 & 0.56 & 134 & 1.4 & 1.40 & $\approx 40$ \\
\hline & & & & 93.6 & 1.34 & & \\
\hline Water & 1.00 & 72.80 & 0.90 & 531 & 1.34 & 1.77 & - \\
\hline
\end{tabular}

of them suppose lignin modification: use of lignin derivatized by the fibrous composite (wool shoddy, consisting of $25 \%$ of viscose, $50 \%$ of wool, and $25 \%$ - polyamide) [23] and so on. Nanosized hydrolytic lignin can be evenly mixed with diesel oil to form a kind of quasi-liquid fuel of a state in between liquid and solid, and thus become a partial substitute for diesel oil [24]. As distinguished from these sorbent materials, the process of Lignosorb production is simple and cost effective.

Hydrophobized HL removes more than $90 \%$ of oil products at the hydrophobized HL:oil product ratio 3:1. Increase the ratio up to $1: 1$ allows removing almost $100 \%$. The buoyancy of the hydrophobized HL sorbent saves for a month in the dependence of the environment conditions. Owing to the high calorific value, much reduced cost, and real horizons for the increase of combustion efficiency the proposed composite lignin-based fuel is the perspective kind of the solid biofuel reducing carbon dioxide footprints. The worked out oil products from several Belarusian enterprises allowed for using as fuels have been successfully overworked by hydrophobized HL into composite fuel pellets.

The rheological behavior of hydrolysis lignin dispersions in various petroleum products: diesel oil and industrial commodity oil was studied. A correlation between viscosity and thixotropy of the dispersions was found and analyzed. It was found that the dispersions containing up to $20 \%$ lignin, are structureless (freely dispersed) systems with a Newtonian flow; the dispersions containing from $20 \%$ to $40 \%$, are coagulationthixotropic semi-structured systems, which can be characterized by a decrease in the effective viscosity with the increasing of shear stress. In the area from $40 \%$ to $50 \%$ the system structuration takes place, whereas at lignin concentration of more than $50 \%$ due 
to capillary forces the nonflowing structured (bonded dispersed) system is formed. The process of solid mass formation depends on the viscosity of the dispersion medium and the particle size of the dispersed phase.

Saturated by different oil products Lignosorb one can granulate or pellet and utilize as a composite solid fuel. The higher calorific value is $32.1-38.8 \mathrm{MJ} / \mathrm{kg}$ in the comparison with 20.9 - 30.1 MJ/kg for coal. The co-firing regime of combustion is possible as well. Less longstanding inflammation stage, more long stable burning stage and less longstanding phase of smoldering in the comparison with wood and Lignosorb burning makes the composite fuel pellets very attractive for using and them to be attached to the line of renewable biofuels. The production of Lignosorb in industrial scale started at the "Bobruisk Plant of Biotechnologies".

\section{Acknowledgements}

The authors would like to thank Science and Technology Department of Zhejiang Province, State Administration of Foreign Experts Affairs, Zhejiang Administration of Foreign Experts Affairs and Zhejiang Shuren University for financial support.

\section{References}

[1] Murygina, V. (2007) Microbes against Oil Spots. Chemistry and Life, 6, 10-15.

[2] Dave, D. and Ghaly, A.E. (2011) Remediation Technologies for Marine Oil Spills: A Critical Review and Comparative Analysis. American Journal of Environmental Science, 7, 423-440. https://doi.org/10.3844/ajessp.2011.423.440

[3] Galimov, E.M., Sevast'yanov, V.S., Karpov, G.A., Kamaleeva, A.I., Kuznetsova, O.V., Konopleva, I.V. and Vlasova, L.N. (2015) Hydrocarbons from a Volcanic Area. Oil Seeps in the Uzon Caldera, Kamchatka. Geochemistry International, 53, 1019-1027. https://doi.org/10.1134/S0016702915120046

[4] Katz, C. and Gauthie, R. (2007) Oil Spill Response Technology Initiation Decision Report to the Pollution Abatement Ashore Program Technical Document, 33 p.

[5] Nguyen, S.T., Feng, J.D., Le, N.T., Le, A.T.T., Hoang, N., Tan, V.B.C. and Duong, H.M. (2013) Cellulose Aerogel from Paper Waste for Crude Oil Spill Cleaning. Industrial \& Engineering Chemistry Research, 52, 18386-18391. https://doi.org/10.1021/ie4032567

[6] Wang, B., Karthikeyan, R., Lu, X.-Y., Xuan, J. and Leung, M.K.H. (2013) Hollow Carbon Fibers Derived from Natural Cotton as Effective Sorbents for Oil Spill Cleanup. Industrial \& Engineering Chemistry Research, 52, 18251-18261. https://doi.org/10.1021/ie402371n

[7] Spotkina, E. and Novoselova, L. (2005) Materials for Adsorptions Purification of Water from Petroleum and Oil Products. Chemistry for Sustainable Development, 13, 359-375.

[8] Rabinovich, M.L. (2014) Lignin By-Products of Soviet Hydrolysis Industry: Resources, Characteristics, and Utilization as a Fuel. Cellulose Chemistry and Technology, 48, 613-631.

[9] Nenkova, S., Herzog, M., Gancheva, V. and Garvanska, L. (2008) Study of the Sorption Properties of Technical Hydrolysis Lignin and Wood Shoddy towards Oil Pollutions. Journal of the University of Chemical Technology and Metallurgy, 43, 217-222.

[10] Sarkanen, K. and Ludwig, C. (1971) Lignin: Occurrence, Formation, Structure and Reactions. Wiley-Interscience, New York, 916 p.

[11] Kovalev, I. (2014) Biogeochemistry of Lignin in Soils. Dostor's Thesis, Moscow, 410 p. 
[12] Karmanov, A., Beliaev, V. and Kocheva, L. (2010) Research of the Lignins Molecules Structure. Chemistry of Plant Raw Material, 1, 27-34.

[13] Nimz, H. (1974) Beech Lignin-Proposal of a Constitutional Scheme. Angewandte Chemie International Edition in English, 13, 313-321. https://doi.org/10.1002/anie.197403131

[14] Kvasnikov, E. and Klushnikova, T. (1981) Microorganisms Is a Destructors of Oil in Water Basins. Kiiv, Naukovadumka, 132 p.

[15] Gosselink, R., Guran, B. and Abeherli, A. (2004) Co-Ordination Network for LigninStandardisation, Production and Applications Adapted to Market Requirements (EUROLIGNIN). Industrial Crops and Products, 20, 121-129.

[16] Levin, B. Influence of Drying Conditions on Lignin Structure. Wood Journal, 4, 24-29.

[17] Zygarlicke, C., Pavlish, J., Gunderson, J. and McCollor, D. (2000) Ash Behavior and Combustion Performance during the Cofiring of Rice Straw Lignin and Coal. Proceedings of the 9th Biennial Bioenergy Conference: Moving Technology into the Marketplace, Buffalo, 15-19 October 2000, 12 p.

[18] Qin, C.D. and Phil, D. (2009) Lignin as Alternative Renewable Fuel. The Alternative Energy e Magazine, 6 .

[19] Brebu, M. and Vasile, C. (2010) Termal Degradation of Lignin-Review. Cellulose Chemistry and Technology, 44, 353-363.

[20] Friedl, A., Padouvas, E., Rotter, H. and Varmuza, K. (2005) Prediction of Heating Values of Biomass Fuel from Elemental Composition. Analytica Chimica Acta, 544, 191-198. https://doi.org/10.1016/j.aca.2005.01.041

[21] Savitskaya, T., Reznikov, I., Scheglov, V., Tsygankova, N., Telysheva, G. and Grinshpan, D. (2011) Rheological Properties of Dispersed Systems on Hydrolysed Lignin and Oil. Journal of Engineering Physics and Tthermophysics, 85, 611-616.

[22] Barnes, H. (1997) Tixotropy-A Review. Journal of Non-Newtonian Fluid Mechanics, 70, 353-363.

[23] Nenkova, S. (2007) Sorption of Oil by the Lignin Fiber Composites. Bioresources, 2, 408418.

[24] Qin, C.D. (2009) Lignin as Alternative Renewable Fuel. The Alternative Energy Magazine, 6. 
Submit or recommend next manuscript to SCIRP and we will provide best service for you:

Accepting pre-submission inquiries through Email, Facebook, LinkedIn, Twitter, etc. A wide selection of journals (inclusive of 9 subjects, more than 200 journals)

Providing 24-hour high-quality service

User-friendly online submission system

Fair and swift peer-review system

Efficient typesetting and proofreading procedure

Display of the result of downloads and visits, as well as the number of cited articles

Maximum dissemination of your research work

Submit your manuscript at: http://papersubmission.scirp.org/

Or contact abb@scirp.org 